\title{
Reduced asymmetry of the hand knob area and decreased sensorimotor u-fiber connectivity in middle-aged adults with autism
}

Janice Hau, Ashley Baker, Chantal Chaaban, Jiwandeep S. Kohli, R. Joanne Jao Keehn, Annika C. Linke, Lisa E. Mash, Molly Wilkinson, Mikaela K. Kinnear, Ralph-Axel Müller, Ruth A. Carper*

Brain Development Imaging Laboratories, Department of Psychology, San Diego State University, San Diego, CA, USA

* Correspondence: Ruth Carper, Brain Development Imaging Laboratories, Department of Psychology, San Diego State University, 6363 Alvarado Ct, Suite 200, San Diego, CA 92120, USA. Email: rcarper@sdsu.edu

Running title: Altered hand knob asymmetry and sensorimotor u-fibers in adults with ASD

Abstract word count: 300

Main text word count: 6575

Tables: 4

Figures: 2

Declarations of interest: none. 
medRxiv preprint doi: https://doi.org/10.1101/2021.07.16.21260584; this version posted July 20, 2021. The copyright holder for this preprint

(which was not certified by peer review) is the author/funder, who has granted medRxiv a license to display the preprint in perpetuity.

It is made available under a CC-BY-NC-ND 4.0 International license .

\begin{abstract}
Individuals with autism spectrum disorder (ASD) frequently present with impairments in motor skills (e.g., limb coordination, handwriting and balance), which are observed across the lifespan but remain largely untreated. Many adults with ASD may thus experience adverse motor outcomes in aging, when physical decline naturally occurs. The 'hand knob' of the sensorimotor cortex is an area that is critical for motor control of the fingers and hands. However, this region has received little attention in ASD research, especially in adults after midlife. The hand knob area of the precentral $\left(\mathrm{PrC}_{\mathrm{hand}}\right)$ and postcentral $\left(\mathrm{PoC}_{\mathrm{hand}}\right)$ gyri was semi-manually delineated in 49 righthanded adults (25 ASD, 24 typical comparison [TC] participants, aged 41-70 years). Using multimodal (T1-weighted, diffusion-weighted, and resting-state functional) MRI, we examined the morphology, ipsilateral connectivity and laterality of these regions. Correlations between hand knob measures with motor skills and autism symptoms, and between structural and functional connectivity measures were also investigated. The right $\mathrm{PrC}_{\text {hand }}$ volume was greater, and typical leftward laterality of $\mathrm{PrC}_{\text {hand }}$ and $\mathrm{PoC}_{\text {hand }}$ volume was lower in the ASD than the TC group. Furthermore, we observed increased mean diffusivity of the right $\mathrm{PoC}$-PrC $\mathrm{C}_{\text {hand }} \mathrm{u}$-fibers in the ASD group. In the ASD group, right $\mathrm{PoC}-\mathrm{PrC}_{\text {hand }} \mathrm{U}$-fiber volume was negatively associated with current autism severity, and positively associated with right $\mathrm{PoC}-\mathrm{PrC}$ hand functional connectivity (FC). Correlations of hand knob measures were observed with manual dexterity and coordination skills but did not survive multiple comparisons correction. Our findings suggest decreased morphological laterality and u-fiber connectivity of the sensorimotor network involved in hand function in middle-aged adults with ASD. The altered morphology may relate to atypical functional asymmetries found in ASD earlier in life, but additionally, could reflect an overreliance on right hemisphere motor circuits over time. The right $\mathrm{PoC}-\mathrm{PrC}$ hand $\mathrm{u}$-fibers may underlie compensatory self-regulation of unwanted core motor behaviors seen in ASD.
\end{abstract}

Keywords: autism, middle-age, hand knob, sensorimotor, hemispheric asymmetry, u-fibers, multimodal MRI, compensation, motor skills 
medRxiv preprint doi: https://doi.org/10.1101/2021.07.16.21260584; this version posted July 20, 2021. The copyright holder for this preprint

(which was not certified by peer review) is the author/funder, who has granted medRxiv a license to display the preprint in perpetuity.

It is made available under a CC-BY-NC-ND 4.0 International license .

\section{Introduction}

Autism spectrum disorder (ASD) is characterized by deficits in social communication, atypical patterns of restricted and repetitive behaviors and sensory abnormalities (American Psychiatric Association, 2013). Impairments in the motor domain are not included in the diagnostic criteria (American Psychiatric Association, 2013). The proportion of individuals with ASD at risk of a motor impairment, however, is estimated to be as high as $86.9 \%$ (Bhat, 2020; Licari et al., 2020). Motor difficulties in ASD are also seldomly reported by diagnosing clinicians (Licari et al., 2020) and remain largely untreated (Bhat, 2020). Motor impairments in individuals with ASD are observed across a wide range of domains (e.g., gross and fine motor coordination, postural stability, balance and grip strength), and are often related to difficulties in motor planning and increased neural noise in the sensorimotor system (Gowen \& Hamilton, 2013). Fine motor impairment in ASD, in particular, is well-documented and has been reported in infancy as early as 6 months (Iverson et al., 2019; Libertus et al., 2014; Sacrey et al., 2018), at the toddler stage (Landa \& Garrett-Mayer, 2006; Lloyd et al., 2013), in childhood (Fuentes et al., 2009; Green et al., 2009; Jasmin et al., 2009; Provost et al., 2007), adolescence (Fuentes et al., 2010; Pan, 2014) and into middle-age (Linke et al., 2019; Thompson et al., 2017; Travers et al., 2015, 2017).

Motor skills are essential for daily living activities required to independently care for oneself, such as eating, dressing, and walking. In children and adults with ASD, positive correlations of manual motor skills with daily living skills, and of motor coordination with daily living skills and adaptive behavior, have been reported (Bremer \& Cairney, 2018; Travers et al., 2017). In aging, the ability to perform these activities is widely used as an indicator of health and disability outcomes (Katz, 1983). Manual motor skills are also found to be robust predictors of functional disability (Rantanen et al., 1999), dependency (Ostwald et al., 1989) and even cognitive impairment (Curreri et al., 2018) in the elderly. In individuals with ASD, there is some evidence that manual motor skills may lag increasingly behind with age (Travers et al., 2017). In an accelerated longitudinal study involving individuals with ASD aged 5-39 years at their first visit, Travers and colleagues (2017) noted that after around age 15 years, grip strength and finger tapping speed in the ASD group diverged further from a typically developing group (with a larger gap in performance than at a younger age). Thus, early motor impairments may be compounded by increased motor problems in adolescence and adulthood in ASD. Reports of an increased prevalence of movement disorders (e.g., parkinsonism) in middle-aged and older adults with ASD have emerged (Croen et al., 2015; Starkstein, Gellar, Parlier, Payne, \& Piven, 2015); however, the literature on aging in ASD remains extremely limited (Piven \& Rabins, 2011).

The anatomical 'hand knob' landmark is a characteristic knob-like shape formed by the central sulcus that defines subareas of the pre and postcentral gyri (Yousry et al., 1997). The hand knob areas elicit hand movements when electrically stimulated (Penfield \& Boldrey, 1937) and consistently show activation during hand movements (Sun et al., 2016; Yousry et al., 1997) in the contralateral hemisphere. Although they are considered to be primarily specialized for hand motor execution, there is evidence of involvement in premotor functions beyond basic motor execution, such as motor planning and coordination. For example, cytoarchitecture of the dorsal premotor cortex (corresponding to Brodmann area 6) extends to portions of the rostral precentral gyrus including the hand knob area (Geyer et al., 1996; Geyer, Matelli, Luppino, \& Zilles, 2000; Rademacher et al., 2001; Rademacher, Rademacher, Caviness, Steinmetz, \& Galaburda, 1993; L. E. White et al., 1997). Stimulation studies of the pre and postcentral hand knob areas show substantial overlap between representations of the hand and other body parts (e.g., mouth, arm, 
medRxiv preprint doi: https://doi.org/10.1101/2021.07.16.21260584; this version posted July 20, 2021. The copyright holder for this preprint (which was not certified by peer review) is the author/funder, who has granted medRxiv a license to display the preprint in perpetuity. It is made available under a CC-BY-NC-ND 4.0 International license .

face) in typical individuals (Catani, 2017; Penfield \& Boldrey, 1937), and a recent study proposed that the hand knob area may be involved in compositional coding of movement across limbs (Willett et al., 2020).

Neuroimaging studies on the hand knob area have mainly been limited to the topics of manual preference (Amunts et al., 1996; Dassonville et al., 1997; S Rose et al., 2012; Volkmann et al., 1998), hand paresis (Gass, Szabo, Behrens, Rossmanith, \& Hennerici, 2001; Peters et al., 2009; Stephen Rose, Guzzetta, Pannek, \& Boyd, 2011) and neurophysiology (Hallett, 2007). To our knowledge, only one MRI study has specifically investigated the hand knob area in ASD, focusing exclusively on the short-range association white matter tracts (i.e., u-fibers) (Thompson et al., 2017). Using deterministic tractography, Thompson and colleagues found evidence of compromised microstructure, specifically reduced fractional anisotropy and increased mean and radial diffusivity, bilaterally in the u-fibers connecting ipsilateral postcentral and precentral hand knob area in right-handed adults (aged 18-45 years) with ASD relative to a control group. Of the limited literature on middle-aged adults with ASD, reduced resting-state functional connectivity of intra and interhemispheric primary sensorimotor and premotor cortical areas has been observed by our group (Linke et al., 2019). This appears to be consistent with the reduced postcentral to precentral u-fiber structural integrity reported in the slightly younger adults with ASD. However, whether these differences in the u-fiber microstructural indices in ASD continue to be seen in middle-age, and what the relationship is between structural and functional connectivity measures of these regions, is unknown.

Although not specifically examining the hand knob area, previous MRI studies have found grey matter abnormalities in the pre and postcentral gyri in ASD. Meta-analyses of voxel-based morphometry studies involving a wide age range from children to adults (including middle-age) have reported decreased grey matter density of the left precentral gyrus (Cauda et al., 2011; NicklJockschat et al., 2012) and left postcentral gyrus (DeRamus \& Kana, 2015) in ASD compared with typical development, and increased grey matter density of the right precentral gyrus in adults (1852 years) with ASD (DeRamus \& Kana, 2015). Moreover, an altered trajectory with age in grey matter density of right precentral gyrus is observed in ASD, declining linearly from age 8 to 50 years while showing a quadratic curve in a typically developing group, with atypically increased grey matter density in ASD in early and middle adulthood (Greimel et al., 2013). This pattern of results raises the possibility of reduced grey matter asymmetry in the pre- and postcentral gyri in adults with ASD. Previous studies on morphological asymmetry, however, have not revealed any group differences in asymmetry in these regions in ASD (Floris, Lai, et al., 2016; Postema et al., 2019). It is possible, however, that laterality varies in different portions of the relatively large regions of the pre and postcentral gyri, and the effect of reduced asymmetry is more localized (e.g., within the hand knob).

The present multimodal MRI study is the first to examine the morphology, structural and functional connectivity, and asymmetry of the hand knob area and links with both motor skills and autism symptoms in middle-aged adults with ASD. Based on the previous literature, we hypothesized reduced asymmetry in volume (accompanied by decreased left and/or increased right volume $)$ in the pre- $\left(\mathrm{PrC}_{\text {hand }}\right)$ and postcentral ( $\left.\mathrm{PoC}_{h a n d}\right)$ hand knob area, and decreased pre- to postcentral hand knob (PoC-PrC $\mathrm{hand}_{\text {) }}$ connectivity in ASD. We also hypothesized that greater leftward laterality of structure (i.e., hand knob volume and u-fiber tract integrity) and functional connectivity would be correlated with improved motor skills and less severe autism symptoms. Additionally, we examined the superior and inferior segments of the pre- and postcentral gyri above and below the hand knob area, in order to determine the specificity of any diagnostic group 
medRxiv preprint doi: https://doi.org/10.1101/2021.07.16.21260584; this version posted July 20, 2021. The copyright holder for this preprint

(which was not certified by peer review) is the author/funder, who has granted medRxiv a license to display the preprint in perpetuity.

It is made available under a CC-BY-NC-ND 4.0 International license .

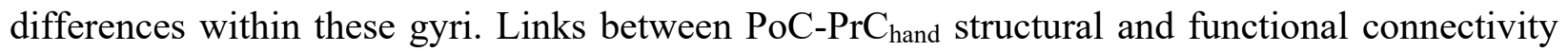
were also investigated.

\section{Methods}

\section{Participants}

Seventy-three participants (35 ASD, 37 typical comparison [TC]), aged 40-70 years, were recruited from San Diego County communities through referrals from autism clinics, service providers (e.g., day programs, group homes) and local advertisement as part of an ongoing longitudinal study. Only individuals with idiopathic ASD and without epilepsy were eligible for participation. TC participants had no personal or family history of autism. All participants had no personal history of other genetic or neurological conditions or serious mental illness. Seventeen datasets were excluded after quality assessment of the imaging data (12 were affected by a hardware issue, 2 scans were incomplete, 3 had low quality anatomical images due to noise, motion or artifacts - see below) and 3 participants were excluded for incidental brain findings. As our study included laterality measures for motor regions, left-handed participants (1 ASD, 2 TC) were excluded. The final sample consisted of 25 ASD and 24 TC participants. For the fMRI analyses, 7 participants were further excluded (4 ASD and 2 TC participants for image artifacts or excessive head motion; 1 ASD participant had no fMRI data). Behavioral measures, including BMAT scores, for the majority of these participants were previously presented in (Linke et al., 2019).

All ASD diagnoses were confirmed by a clinical psychologist according to DSM-5 criteria (American Psychiatric Association, 2013), and supported by module 4 of the Autism Diagnostic Observation Schedule, $2^{\text {nd }}$ edition (ADOS-2) (Lord et al., 2002) (current ADOS scores were not available for one participant due to administrator error, however this individual met ASD criteria on a research-related ADOS within the preceding 5 years). Intelligence quotient (IQ) was assessed with the Wechsler Abbreviated Scale of Intelligence, $2^{\text {nd }}$ edition (WASI-II) (Wechsler, 2011). Dichotomous hand preference (left/ambidextrous or right) was determined for all participants based on a personal history questionnaire completed by the participant or caregiver in response to the question "With which hand does s/he eat, brush teeth, write, etc.?", in line with (Perelle \& Ehrman, 2005). The Edinburgh Handedness Inventory (EHI) (Oldfield, 1971) was used to measure degree of handedness and was available for 23 ASD and 23 TC participants. The EHI consists of a self-report checklist in which participants indicate their hand preference (left, right, or if really indifferent, both left and right) across ten different actions (e.g., "write a letter with a pencil", "throw a baseball", "strike a match"), and a final score is calculated as follows: (\# right - \# left) / (\# right + \# left) x 100. The self-reported EHI scores corresponded to dichotomous hand preference for all participants who completed the EHI. Motor function was assessed using the short form version of the Bruininks Motor Ability Test (BMAT) (Bruininks \& Bruininks, 2012). Five subcategories of motor behavior were evaluated: fine motor (e.g., drawing a line through a curved path), manual dexterity (e.g., transferring pennies), coordination (e.g., bouncing and catching a ball), balance and mobility (e.g., standing on one leg), and strength and flexibility (e.g., grip strength).

The study was approved by the institutional review boards of the San Diego State University and University of California, San Diego. All participants were screened for MRI contraindications (e.g., claustrophobia, ferrous material in body). All participants or their 
medRxiv preprint doi: https://doi.org/10.1101/2021.07.16.21260584; this version posted July 20, 2021. The copyright holder for this preprint

(which was not certified by peer review) is the author/funder, who has granted medRxiv a license to display the preprint in perpetuity.

It is made available under a CC-BY-NC-ND 4.0 International license .

conservators provided written informed consent before participation, and participants were compensated for their time.

\section{Image acquisition}

MRI data were collected at the Center for Functional Magnetic Resonance Imaging (CFMRI, University of California, San Diego) on a 3T GE Discovery MR750 scanner using a 32channel head coil. A high resolution anatomical T1-weighted image (repetition time $[\mathrm{TR}]=8.776$ $\mathrm{ms}$, echo time $[\mathrm{TE}]=3.656 \mathrm{~ms}, 8^{\circ}$ flip angle, $320 \times 320$ matrix, $0.8 \mathrm{~mm}^{3}$ resolution) was acquired using an MPRAGE sequence with real-time prospective motion correction (PROMO; White et al., 2010). Diffusion-weighted images were acquired with 46 non-colinear directions at $b=1500$ (13 ASD and 9 TC participants) or $1000 \mathrm{~s} / \mathrm{mm}^{2}$ (12 ASD and 15 TC participants) and 6 interspersed volumes at $\mathrm{b}=0 \mathrm{~s} / \mathrm{mm}^{2}(\mathrm{TR}=4000 \mathrm{~ms}, \mathrm{TE}=89 \mathrm{~ms}$, multi-band factor $=3,27 \mathrm{slices} / \mathrm{band}, 24 \mathrm{~cm}$ field of view [FOV], $1.7 \mathrm{~mm}^{3}$ resolution) with reversed (anterior-posterior) phase encoding to correct for susceptibility distortions and improve signal-to-noise ratio. Resting-state functional MRI images were acquired using a multi-band EPI sequence (2 runs x 6 minute duration each, $\mathrm{TR}=800 \mathrm{~ms}, \mathrm{TE}=35 \mathrm{~ms}$, multi-band factor $=8,52^{\circ}$ flip angle, $20.8 \mathrm{~cm} \mathrm{FOV}, 2 \mathrm{~mm}^{3}$ resolution) with a 20s reverse phase-encoded calibration scan pair using identical imaging parameters to correct for susceptibility-induced distortions. Before each functional MRI scan, participants were given the following instructions: "Keep your eyes on the cross. Let your mind wander, relax, but please stay as still as you can. Try not to fall asleep." Eye status was monitored throughout the duration of the scan using an in-bore camera to ensure participant compliance.

\section{Data preprocessing}

FreeSurfer 5.3.0 was used to preprocess the anatomical images using the standard pipeline (i.e., skull stripping, intensity normalization, gray-white matter segmentation) and to perform cortical surface reconstruction (Dale et al., 1999; Fischl et al., 1999). The anatomical images and surfaces were visually inspected, and any images with inaccurate surfaces or excessive image artifacts (e.g., ghosting, ringing) were excluded. For both diffusion-weighted and functional MRI data, susceptibility-induced off-resonance fields were estimated and corrected from the reversed phase-encoded image pairs using TOPUP (Andersson et al., 2003). For the diffusion-weighted images, we first applied denoising by eliminating the noise component in the patch-level PCAdomain (Veraart et al., 2016). Eddy current and susceptibility-induced distortions, inter- and intravolume head motion and signal dropout incorporating information from both individual slices and multi-band slice groupings (Andersson et al., 2017) were then corrected in a single interpolation step using EDDY from the FMRIB Software Library (FSL) 5.0.11 (Andersson et al., 2016; Andersson \& Sotiropoulos, 2016). The b-vectors were rotated according to the motion realignment. Functional MRI preprocessing included rigid-body realignment for motion correction and non-linear registration to Montreal Neurological Institute (MNI) space (SPM12) and scrubbing of motion outliers, band-pass filtering using a temporal filter of $0.008-0.08 \mathrm{~Hz}$, and nuisance regression (including motion parameters and their derivatives as well as time-series derived from cerebrospinal fluid and white matter) using the Functional Connectivity (Conn) Toolbox (Whitfield-Gabrieli \& Nieto-Castanon, 2012).

For purposes of group matching, in-scanner head motion was quantified in two ways for the diffusion-weighted images: average root mean squared displacement excluding in the phase- 
medRxiv preprint doi: https://doi.org/10.1101/2021.07.16.21260584; this version posted July 20, 2021. The copyright holder for this preprint (which was not certified by peer review) is the author/funder, who has granted medRxiv a license to display the preprint in perpetuity. It is made available under a CC-BY-NC-ND 4.0 International license .

encoding direction across all brain voxels with respect to the first volume (absolute RMSD) and with respect to the preceding volume (relative RMSD). RMSD was also calculated from the fMRI realignment parameters and averaged across runs to quantify head motion during the functional MRI scans.

\section{Delineation of the hand knob regions of interest}

Given the interindividual variability in the location (Sun et al., 2012) and morphology (Caulo et al., 2007) of the hand knob along the central sulcus, the regions of interest (ROIs) for the pre $\left(\mathrm{PrC}_{\text {hand }}\right)$ and postcentral $\left(\mathrm{PoC}_{\text {hand }}\right)$ hand $\mathrm{knob}$ areas were semi-manually delineated in each participant. Automatic parcellations of the pre and postcentral gyri (Desikan et al., 2006) were performed for each participant and used as starting regions, from which $\mathrm{PrC}_{\text {hand }}$ and $\mathrm{PoC}_{\text {hand }} \mathrm{Were}$ subsequently delineated, to ensure that the final ROIs correspond with consistent pre and postcentral cortical boundaries and with grey matter tissue. From the starting parcels, manual segmentations of the hand knob ROIs were performed by one trained operator (AB). Fsleyes (McCarthy, 2018) was used to visualize and edit the ROIs with the participants' T1-weighted image underlay. First, the hand knob landmark, commonly identified as an omega (but also epsilon or null) shape on the precentral gyrus (Caulo et al., 2007), was located in the axial plane in each hemisphere (Figure 1A). Then the starting regions were manually edited by removing areas surrounding the hand knob (i.e., supero-posterior and infero-anterior to the hand knob [e.g., omega] landmark) until only the hand knob remained (Figure 1B). As the hand knob was most identifiable on the precentral gyrus, delineation of the precentral hand knob $\left(\mathrm{PrC}_{\mathrm{hand}}\right)$ was performed first and the boundaries of the postcentral hand knob ( $\left.\mathrm{PoC}_{\mathrm{hand}}\right)$ were extrapolated following a perpendicular line from the superior and inferior limits of $\mathrm{PrC}_{\text {hand }}$ to the adjacent postcentral gyrus. The T1-weighted images were rigid-body registered to diffusion space using a boundary-based approach (Greve \& Fischl, 2009) and the parcellated regions were registered using the same registration matrix with nearest neighbor interpolation. All operators were trained by an experienced anatomist $(\mathrm{JH})$ until agreement was reached on the location and spatial extent of the ROIs in 10 practice participants. All operators were blind to the participants' diagnostic group.

To assess intra-rater reliability, the hand knob regions were delineated a second time by author $\mathrm{AB}$ in a subset of 15 participants. To assess inter-rater reliability, a second trained operator (CC) delineated hand knob regions in the same subset of participants. Intra-class correlation coefficients (ICC) with two-way random effects showed good overall intra-rater reliability between hand knob volume measurements $\left(\mathrm{PrC}_{\text {hand }}\right.$ : average measure $\mathrm{ICC}=.647, \mathrm{p}=.003$; $\mathrm{PoC}_{\text {hand: }}$ : average measure $\mathrm{ICC}=.823, \mathrm{p}<.001)$ and their laterality indices [LI] (LI PrC $\mathrm{Pand}_{\text {and }}$ average measure $\mathrm{ICC}=.755, \mathrm{p}=.006$; $\mathrm{LI} \mathrm{PoC}_{\text {hand: }}$ average measure $\left.\mathrm{ICC}=.828, \mathrm{p}=.001\right)$. Between-rater reliability was also good overall $\left(\mathrm{PrC}_{\text {hand }}\right.$ : average measure $\mathrm{ICC}=.667, \mathrm{p}=.002 ; \mathrm{PoC}_{\text {hand }}$ : average measure $\mathrm{ICC}=.855, \mathrm{p}<.001$; $\mathrm{LI} \mathrm{PrC}_{\text {hand }}$ : average measure $\mathrm{ICC}=.770, \mathrm{p}=.005$.; $\mathrm{LI}_{\mathrm{PoC}}$ hand: average measure $\mathrm{ICC}=.785, \mathrm{p}=.003$ ). Additionally, we calculated overlap coefficients $(\mathrm{OC})$ for $\mathrm{PrC}_{\text {hand }}$ and $\mathrm{PoC}_{\text {hand }}$ which showed good spatial correspondence within $\left(\mathrm{PrC}_{\text {hand: }}\right.$ mean $\mathrm{OC}$ [min, $\left.\max \right]=.85$ [.53, .99]; PoChand: $.91[.70, .99])$ and between $\left(\mathrm{PrC}_{\text {hand: }} .87[.74, .99]\right.$; PoC $\left.\mathrm{C}_{\text {hand: }} .88[.55, .96]\right)$ raters.

Since the hand knob ROIs were delineated in the native diffusion space and therefore could be subject to variations in brain alignment with respect to the cardinal axes, we extracted the root mean squared deviation in roll, pitch and yaw rotations (RMSD ${ }_{\text {rot }}$ ) from the affine transformations between diffusion and MNI space for each participant. Independent t-tests showed that the groups marginally differed in $\mathrm{RMSD}_{\text {rot }}(p=.082$; TC mean [SD]: 9.66 [3.60]; ASD: 7.97 [3.05]). This 
medRxiv preprint doi: https://doi.org/10.1101/2021.07.16.21260584; this version posted July 20, 2021. The copyright holder for this preprint (which was not certified by peer review) is the author/funder, who has granted medRxiv a license to display the preprint in perpetuity.

It is made available under a CC-BY-NC-ND 4.0 International license .

measure was included as an additional covariate for the anatomical measures in our statistical model to control for brain image rotation.

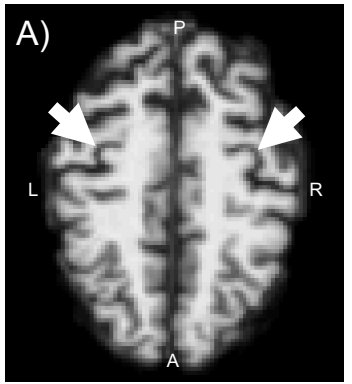

B) Automatically parcellated 'starting regions'
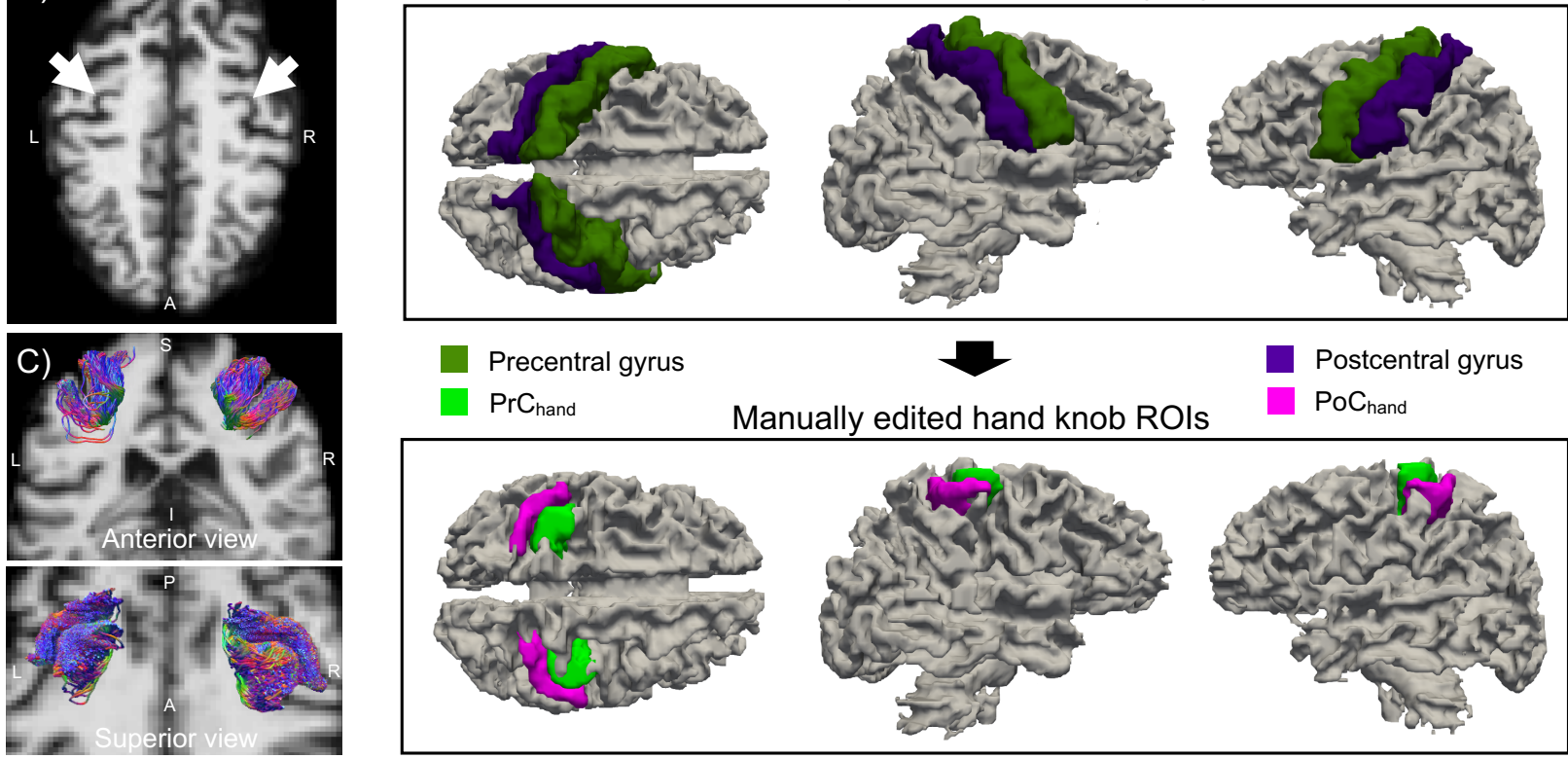

$\mathrm{PrC}_{\text {hand }}$

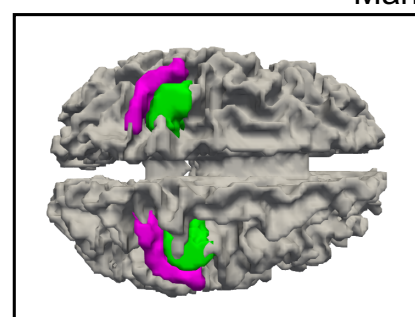

Manually edited hand knob ROls

Postcentral gyrus

$\mathrm{PoC}_{\text {hand }}$

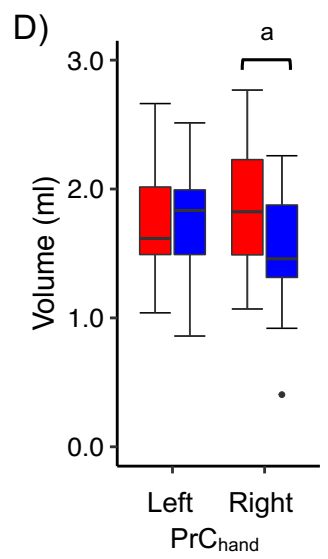

E)
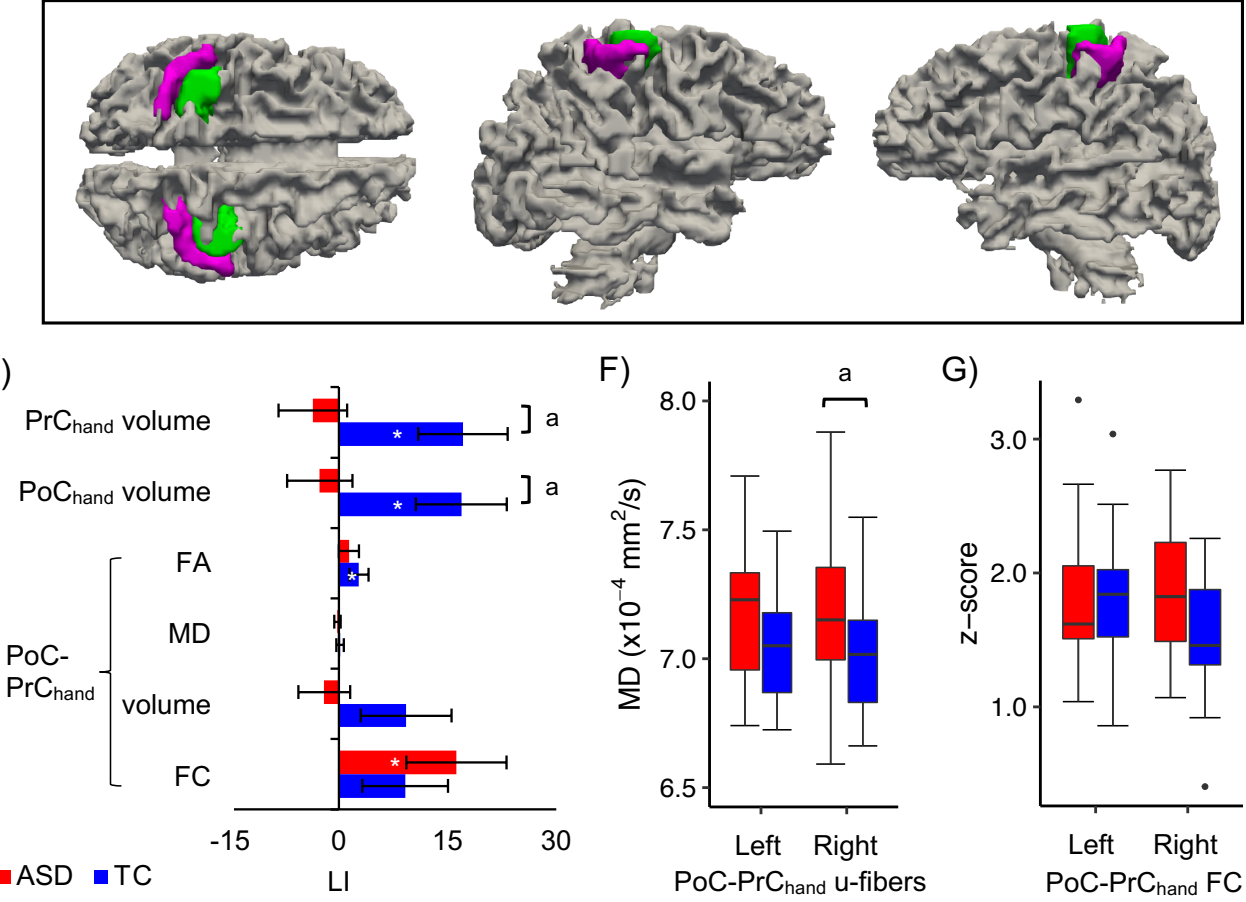

Figure 1. A-C) Identification and delineation of the hand knob regions and u-fibers. A) The typical omega-shaped landmark (white arrows) used to identify the hand knob in the axial plane of a representative participant with ASD (aged 46-50 years). B) The automatically parcellated pre and postcentral regions (upper row) were manually edited to define the pre ( $\mathrm{Pr} \mathrm{C}_{\mathrm{hand}}$ ) and postcentral ( $\mathrm{PoC}_{\mathrm{hand}}$ ) hand knob regions of interest (lower row). C) Streamline tractography of the u-fiber tracts connecting ipsilateral $\mathrm{PoC}_{\text {hand }}$ and $\mathrm{PrC}_{\text {hand }}$ from the same participant. D-G) Alterations in hand knob morphometry, laterality and PoC-PrC connectivity in middle-aged adults with ASD. The plots show D) increased right $\mathrm{PrC}_{\text {hand }}$ volume, E) reduced laterality of $\mathrm{PrC}_{\text {hand }}$ and $\mathrm{PoC}_{\text {hand }}$ knob volume (LI of other hand knob measures are also shown), and F) increased MD in the right PoC-PrC $\mathrm{C}_{\text {hand }} \mathrm{u}$-fiber tract in the ASD group. G) Medium size group effects were also observed for left $\mathrm{PoC}$-PrChand $\mathrm{u}$-fiber MD (increased in ASD) and right PoC-PrC $\mathrm{Chan}_{\mathrm{FC}}$ (decreased in ASD). ${ }^{\mathrm{a}}$ $q<.10$ significance level; ${ }^{*}$ LI measures that differed from zero $(p<.05$, uncorrected). Standard errors of the means are shown in the bar plot. 
medRxiv preprint doi: https://doi.org/10.1101/2021.07.16.21260584; this version posted July 20, 2021. The copyright holder for this preprint

(which was not certified by peer review) is the author/funder, who has granted medRxiv a license to display the preprint in perpetuity.

It is made available under a CC-BY-NC-ND 4.0 International license .

\section{Fiber tractography and diffusion scalar maps}

Fiber tractography was performed using the MRtrix3 software package (Tournier et al., 2019). Response functions were estimated for each tissue type (grey matter, white matter and cerebrospinal fluid) using an unsupervised algorithm (Dhollander et al., 2019). Fiber orientation distributions were estimated using multi-tissue constrained spherical deconvolution (Jeurissen et al., 2014), and intensity normalization was applied across tissue-specific distributions to minimize spurious peaks driven by single-tissue intensities. Sensorimotor (PoC-PrC) u-fibers were obtained by performing anatomically constrained probabilistic tractography (Smith et al., 2012) on the fiber orientation distributions using ipsilateral $\mathrm{PrC}_{\text {hand }}$ and $\mathrm{PoC}_{\text {hand }}$ as both seed and target regions, that were reversed to track in both directions to control for biases in tracking direction, with 5000 randomly placed seeds per voxel (minimum length $=10 \mathrm{~mm}$, maximum length $=100 \mathrm{~mm}, 45^{\circ}$ angle threshold, step size $=1 \mathrm{~mm}$ ). The reverse-track pairs were combined to create the final tracts (for an example, see Figure 1C) and were consistent with descriptions of these u-fibers in previous studies (Catani et al., 2012; Guevara et al., 2017; Pron et al., 2021; Rojkova et al., 2015; Viganò et al., 2019).

The diffusion data were fitted to the tensor model at each voxel using weighted least squares to create diffusion tensor imaging scalar maps (fractional anisotropy [FA] and mean [MD],). The scalar maps were harmonized across acquisition protocols (b-value) using an empirical Bayes-based method (Johnson et al., 2007) shown to be robust for small sample sizes and biased samples (ComBat; Fortin et al., 2017).

\section{Morphological, connectivity and laterality measures}

The $\mathrm{PrC}_{\text {hand }}$ and $\mathrm{PoC}_{\text {hand }} \mathrm{ROI}$ volumes of each participant were calculated as the total volume of voxels occupied by each ROI in the subjects' diffusion space using FSLstats. In subsequent tests of surface area (SA) and cortical thickness (CT), the regions were re-registered to anatomical space, projected to the cortical mid-surface, smoothed with a Gaussian kernel (full width at half maximum $=6 \mathrm{~mm}$ ) and threshold at $20 \%$ probability in FreeSurfer. The threshold was chosen to maximize areal coverage while minimizing overlap between $\mathrm{PrC}_{\text {hand }}$ and $\mathrm{PoC}_{\text {hand }} \mathrm{SA}$ and CT were averaged across the ROI.

The $u$-fiber tract measures were extracted by averaging the mean value along streamlines from the diffusion scalar maps. The volume of each u-fiber tract was calculated as the total volume of voxels occupied by the tract.

Blood oxygenation level-dependent time-series from the same individual-subject ROIs (warped to MNI standard space) were averaged across voxels, and FC was estimated between ipsilateral $\mathrm{PrC}_{\text {hand }}$ and $\mathrm{PoC}_{\text {hand }}$ using Fisher $z$-transformed bivariate Pearson correlations.

To analyze laterality of the anatomical and connectivity features, a laterality index (LI) was calculated for all measures as follows: $L I=(L e f t-R i g h t) / \frac{(L e f t+R i g h t)}{2} \times 100$, where positive values indicate lateralization in the dominant (left) hemisphere for motor function. Note that this differs from the EHI scores where positive values indicate dominant (right) hand motor function.

Additionally, for each participant, total brain volume was calculated from the tissue maps segmented from the b0 image using FSL's FAST (Zhang et al., 2001) as the total volume of grey and white matter voxels. 
medRxiv preprint doi: https://doi.org/10.1101/2021.07.16.21260584; this version posted July 20, 2021. The copyright holder for this preprint

(which was not certified by peer review) is the author/funder, who has granted medRxiv a license to display the preprint in perpetuity.

It is made available under a CC-BY-NC-ND 4.0 International license .

In order to determine the anatomical specificity of our findings, analyses were performed on the pre- and postcentral gyri parcels above $\left(\mathrm{PrC}_{\text {upper }}\right.$ and $\mathrm{PoC}_{\text {upper, }}$, respectively) and below ( $\mathrm{PrC}_{\text {lower }}$ and $\mathrm{PoC}_{\text {lower, }}$ respectively) the hand knob using the same methods for extracting and analyzing the hand knob measures. (See Supplementary Figures 1-2 for the upper and lower $\operatorname{PrC}$ and $\mathrm{PoC}$ parcels and upper and lower PoC-PrC u-fibers in relation to the hand knob parcels in a representative subject).

\section{Statistical analysis}

Independent samples $t$-tests and Chi-square tests were used to compare diagnostic groups on demographic, confounding variables (e.g., in-scanner head motion) and motor performance. One-way analyses of covariance (ANCOVAs) were used to test for effects of diagnosis controlling for age (morphological measures); age, relative RMSD and a dummy variable coding for b-value protocol (u-fiber measures); and age and average RMSD (FC measures). Total brain volume (TBV) (morphological measures) and tract volume (diffusion measures), known to bias diffusion measures due to partial volume effects (Vos et al., 2011), were additionally included in the model to test potential confounding factors. One-sample $t$-tests (two-tailed) against a null-hypothesis of 0 were used to test for laterality of each hand knob measure in the diagnostic groups separately, in addition to analyzing LI for group differences. One TC participant was deemed an outlier ( $>3$ standard deviations from the group mean) and was removed from subsequent analyses of the left PoC-PrC $\mathrm{C}_{\text {hand }} \mathrm{u}$-fiber tract and the tract's LI. We controlled for multiple comparisons using the false discovery rate (FDR) (Benjamini \& Hochberg, 1995) at $q<.10$ across all hand knob measures (18 comparisons)=

Pearson partial correlations were performed between the hand knob measures and BMAT subscales (Manual Dexterity, Coordination, and Strength and Flexibility) for each group separately, partialing out the same variables as described for the ANCOVAs above. Due to the limited range of scores in the Fine Motor and Balance and Mobility BMAT subscales in both groups, these were not included in our analyses. Given the ordinal nature of the ADOS-2 measures, Spearman rank-order partial correlations were performed between hand knob measures and the Social Affect, Restricted and Repetitive Behavior [RRB], and Comparison [CS] scores of the ADOS-2 in the ASD group, partialling out the same variables as described for the ANCOVAs above. We applied FDR correction on 18 hand knob measures for each subscale per group.

To explore relationships between structural and functional connectivity, partial Pearson correlations were performed between sensorimotor hand knob u-fiber and functional connectivity measures ipsilaterally, controlling for age, relative RMSD (dMRI motion), average RMSD (fMRI motion) and b-value protocol in each diagnostic group, separately. We applied FDR correction on 3 tract measures [FA, MD and volume] x 3 FC measures [left, right and LI] (9 comparisons) per diagnostic group.

Statistical analyses were conducted in R (Core R Team, 2019) and plots were created using the package ggplot2 (Wickham, 2016).

\section{Results}

The diagnostic groups did not differ on age, sex, degree of handedness, IQ, motion dropout or absolute RMSD (Table 1; all $p \mathrm{~s}>.05$ ). The ASD group had lower performance in Manual Dexterity, Coordination and Strength and Flexibility compared with the TC group (Table 1). As 
the groups marginally differed in relative RMSD, this motion measure was included as a covariate in analyses examining diffusion-weighted imaging measures. While the percent difference between groups in motion dropout was $43.1 \%$, it was well below $1 \%$ of all slices in all participants, and affected slices were replaced with predicted values during preprocessing with the EDDY tool (Andersson et al., 2016). The groups did not differ in TBV. The sample included in the FC analyses did not differ between groups on age $(p=.641)$, sex $(p=.691)$, degree of handedness $(p=.464)$, IQ (non-verbal: $p=.752$, verbal: $p=.328)$ or motion $(p=.170)$.

Table 1. Participant characteristics and group matching.

\begin{tabular}{|c|c|c|c|c|c|c|}
\hline & \multicolumn{2}{|c|}{$\operatorname{ASD}(n=25)$} & \multicolumn{2}{|c|}{$\mathrm{TC}(\mathrm{n}=24)$} & \multirow[b]{2}{*}{$p^{*}$} & \multirow[b]{2}{*}{$\begin{array}{c}\% \\
\text { diff }\end{array}$} \\
\hline & Mean $\pm \mathrm{S}$ & [range] & Mean $\pm s$ & [range] & & \\
\hline $\operatorname{Sex}(M / F)$ & \multicolumn{2}{|c|}{$20 / 5$} & \multicolumn{2}{|c|}{$21 / 3$} & 0.70 & -- \\
\hline Age (years) & $51.7 \pm 6.9$ & [41-67] & $51.6 \pm 7.0$ & [41-70] & 0.95 & 0.1 \\
\hline $\mathrm{EHI}^{\dagger}$ & $81 \pm 30$ & {$[11-100]$} & $86 \pm 18$ & {$[40-100]$} & 0.47 & -1.6 \\
\hline WASI-2 Verbal IQ & $103 \pm 24$ & {$[52-160]$} & $114 \pm 14$ & [85-144] & 0.07 & -2.4 \\
\hline Non-verbal IQ & $108 \pm 22$ & [56-138] & $112 \pm 12$ & [90-135] & 0.36 & -1.1 \\
\hline Full-scale IQ & $106 \pm 23$ & {$[51-143]$} & $115 \pm 12$ & [92-138] & 0.09 & -2.0 \\
\hline ADOS-2 Social Affect & $10.2 \pm 3.6$ & {$[5-19]$} & \multicolumn{2}{|c|}{--} & -- & -- \\
\hline $\mathrm{RRB}^{\ddagger}$ & $3.8 \pm 1.8$ & {$[1-8]$} & \multicolumn{2}{|c|}{--} & -- & -- \\
\hline Comparison Score & $7.4 \pm 1.8$ & {$[3-10]$} & \multicolumn{2}{|c|}{--} & -- & -- \\
\hline BMAT $^{\S}$ Fine Motor & $13 \pm 1$ & {$[8-15]$} & $14 \pm 1$ & {$[12-14]$} & 0.11 & -0.9 \\
\hline Manual Dexterity & $12 \pm 3$ & {$[2-16]$} & $14 \pm 1$ & {$[12-17]$} & $<.01$ & -4.3 \\
\hline Coordination & $9 \pm 2$ & {$[4-10]$} & $10 \pm 1$ & {$[7-10]$} & $<.01$ & -3.2 \\
\hline Strength \& Flexibility & $14 \pm 4$ & [6-18] & $17 \pm 2$ & {$[10-18]$} & $<.01$ & -4.9 \\
\hline Balance \& Mobility & $9 \pm 1$ & [7-9] & $9 \pm 1$ & [6-9] & 0.89 & -0.1 \\
\hline Total brain volume $\left(\mathrm{cm}^{3}\right)$ & $1516 \pm 185$ & [1085-1783] & $1493 \pm 138$ & [1096-1686] & 0.61 & 0.4 \\
\hline Motion dropout (\% slices) & $0.05 \pm 0.13$ & {$[0-0.64]$} & $0.01 \pm 0.12$ & {$[0-0.06]$} & 0.13 & 43.1 \\
\hline dMRI absolute RMSD & $1.34 \pm 1.17$ & {$[0.34-5.34]$} & $1.13 \pm 0.59$ & {$[0.43-2.78]$} & 0.44 & 4.2 \\
\hline dMRI relative RMSD & $0.43 \pm 0.26$ & {$[0.16-1.03]$} & $0.31 \pm 0.11$ & {$[0.17-0.59]$} & 0.05 & 7.8 \\
\hline $\begin{array}{l}\text { fMRI RMSD (average across } \\
\text { runs) }\end{array}$ & $0.10 \pm 0.05$ & {$[0.04-0.19]$} & $0.09 \pm 0.03$ & {$[0.04-0.19]$} & 0.17 & 4.7 \\
\hline
\end{tabular}

${ }^{*}$ T-tests; Chi-Square test for sex.

'EHI unavailable for 3 participants (2 ASD, 1 TC).

\#ADOS-2 scores unavailable for 1 ASD participant due to administrator error (see text).

${ }^{\S}$ BMAT was not completed in 2 participants (1 ASD, 1 TC).

" 2 participants ( $1 \mathrm{ASD}, 1 \mathrm{TC}$ ) were excluded for excessive image artifacts, 4 participants were excluded to match for head motion ( 3 ASD, 1 TC) and 1 ASD participant did not have functional MRI data.

Abbreviations: EHI=Edinburgh Handedness Inventory; WASI-2=Wechsler Abbreviated Scale of Intelligence, $2^{\text {nd }}$ edition; ADOS-2=Autism Diagnostic Observation Scale, $2^{\text {nd }}$ edition; RRB=Restricted and Repetitive Behaviors; BMAT=Bruininks Motor Assessment Scale - Short form; RMSD=average voxelwise root mean square displacement (head motion); diff=difference between groups. 
medRxiv preprint doi: https://doi.org/10.1101/2021.07.16.21260584; this version posted July 20, 2021. The copyright holder for this preprint

(which was not certified by peer review) is the author/funder, who has granted medRxiv a license to display the preprint in perpetuity.

It is made available under a CC-BY-NC-ND 4.0 International license .

\section{Hand knob morphology and laterality}

The hand knob ROIs were successfully delineated in all participants and the proportion of each morphological variant ( $80.6 \%$ omega, $17.3 \%$ epsilon and $2.0 \%$ null; Supplementary Table 1$)$ was in line with previous studies(Caulo et al., 2007).

ANCOVAs indicated that right $\mathrm{PrC}_{\text {hand }}$ volume was significantly increased in the ASD compared with the TC group (Figure 1D; Table 2), while no group difference was found for left PrChand volume.

Using one-sample $t$-tests we observed significant leftward volume asymmetry of $\mathrm{PrC}_{\text {hand }}$ and $\mathrm{PoC}_{\text {hand }}$ in the TC ( $p=.011$; Figure $\left.1 \mathrm{E}\right)$ but not in the ASD group. For the laterality indices, there were significant diagnosis effects for both $\mathrm{PrC}_{\text {hand }}$ and $\mathrm{PoC}_{\text {hand }}$ volume, $(\mathrm{ASD}<\mathrm{TC}$; Figure $1 \mathrm{E}$; Table 2). These group effects remained when additionally controlling for TBV, RMSD $\mathrm{D}_{\text {rot, }}$ and when we ran the analysis on only strongly right-handed individuals (EHI scores $\geq 80$; remaining sample=17 ASD, 19 TC), to ensure the effect was not driven by weakly right-handed individuals (Supplementary Table 2).

Post hoc ANCOVAs on CT and SA were run to further investigate the regions that showed group differences in hand knob volume. There was a significant group effect in right $\mathrm{PrC}_{\text {hand }} \mathrm{SA}$ $\left(p=.012\right.$, partial $\eta^{2}=.129$, ASD $>$ TC $)$, but not CT $\left(p=.237\right.$, partial $\left.\eta^{2}=.030\right)$. For the laterality indices these were not significant, however, small to medium group effects were observed in $\mathrm{SA}\left(\operatorname{PrC} \mathrm{C}_{\text {hand: }}\right.$ : $p=.014$, partial $\eta^{2}=.125$; PoC $\mathrm{C}_{\text {hand }} p=.063$, partial $\eta^{2}=.073$; both $\mathrm{ASD}<\mathrm{TC}$ ), in contrast to $\mathrm{CT}$ (PrC $\mathrm{Cand}_{\mathrm{h}} p=.856$, partial $\eta^{2}=.001 ; \mathrm{PoC}_{\text {hand: }} p=.238$, partial $\eta^{2}=.030$ ).

\section{Hand knob PoC-PrC structural and functional connectivity}

We observed a significant diagnosis effect in $\mathrm{MD}$ of right $\mathrm{PoC}-\mathrm{PrC}_{\text {hand }}$ tract, which was increased in the ASD compared to TC group (Figure 1F; Table 2). The effect remained when additionally controlling for tract volume $(p=.017)$. Although $\mathrm{MD}$ for the left PoC-PrC $\mathrm{C}_{\text {hand }}$ tract did not survive FDR correction, it was initially significant $(\mathrm{p}=.039)$ with a small effect size (Figure $1 \mathrm{~F}$; Table 2). This is noteworthy given that group differences in these $\mathrm{u}$-fiber tracts bilaterally have been previously reported in ASD. We also observed a medium effect size of group in right PoC$\mathrm{PrC}_{\text {hand }} \mathrm{FC}$, which was decreased in the ASD relative to TC group, but it did not survive FDR correction (Figure 1G; Table 2).

One-sample $t$-tests revealed leftward laterality of FA in the TC ( $p=.046$; Figure 1E), but not in the ASD group, and leftward laterality of $\mathrm{PoC}-\mathrm{PrC}_{\text {hand }} \mathrm{FC}$ in the ASD group that was not found in the TC group. No group differences were found in LI of PoC-PrChand $\mathrm{u}$-fiber or FC measures. 
Table 2. Results of the ANCOVAs performed on the hand knob measures and their group means and standard deviations.

\begin{tabular}{|c|c|c|c|c|c|c|c|}
\hline Region & Measure & df & $p$ & $q$ & Partial $\eta^{2}$ & $\mathrm{ASD}$ mean $\pm \mathrm{SD}$ & $\mathrm{TC}$ mean $\pm \mathrm{SD}$ \\
\hline Left $\operatorname{PrC}_{\text {hand }}$ & Volume & 1,46 & 0.962 & 0.97 & $<0.001$ & $1.80 \pm 0.52$ & $1.79 \pm 0.49$ \\
\hline Right $\operatorname{PrC}_{\text {hand }}$ & Volume & 1,46 & 0.012 & $0.08^{\mathrm{a}}$ & 0.129 & $1.85 \pm 0.46$ & $1.52 \pm 0.43$ \\
\hline Left $\mathrm{PoC}_{\text {hand }}$ & Volume & 1,46 & 0.262 & 0.39 & 0.027 & $2.32 \pm 0.48$ & $2.52 \pm 0.70$ \\
\hline Right $\mathrm{PoC}_{\text {hand }}$ & Volume & 1,46 & 0.210 & 0.38 & 0.034 & $2.39 \pm 0.55$ & $2.17 \pm 0.67$ \\
\hline PrChand $_{\text {han }}$ & LI Volume & 1,46 & 0.011 & $0.08^{\mathrm{a}}$ & 0.133 & $-3.6 \pm 24.7$ & $17.1 \pm 30.2$ \\
\hline PoChand & LI Volume & 1,46 & 0.015 & $0.08^{\mathrm{a}}$ & 0.123 & $-2.6 \pm 22.5$ & $16.9 \pm 30.7$ \\
\hline \multirow{4}{*}{ Left PoC-PrChand $\mathrm{U}$-fibers } & FA & 1,43 & 0.143 & 0.29 & 0.042 & $0.36 \pm 0.02$ & $0.37 \pm 0.02$ \\
\hline & MD & 1,43 & 0.039 & 0.13 & 0.085 & $7.16 \pm 0.24$ & $7.03 \pm 0.22$ \\
\hline & Volume & 1,43 & 0.972 & 0.97 & $<0.001$ & $9.94 \pm 2.37$ & $9.65 \pm 1.97$ \\
\hline & FA & 1,44 & 0.899 & 0.97 & $<0.001$ & $0.35 \pm 0.03$ & $0.36 \pm 0.03$ \\
\hline \multirow[t]{3}{*}{ Right PoC-PrChand u-fibers } & MD & 1,44 & 0.018 & $0.08^{\mathrm{a}}$ & 0.102 & $7.18 \pm 0.28$ & $7.01 \pm 0.23$ \\
\hline & Volume & 1,44 & 0.237 & 0.39 & 0.029 & $10.03 \pm 1.97$ & $9.03 \pm 2.28$ \\
\hline & LIFA & 1,43 & 0.389 & 0.50 & 0.017 & $1.4 \pm 6.9$ & $2.8 \pm 6.3$ \\
\hline \multirow[t]{2}{*}{ PoC-PrChand $\mathrm{U}$-fibers } & LI MD & 1,43 & 0.747 & 0.90 & 0.002 & $-0.2 \pm 2.2$ & $0.2 \pm 2.5$ \\
\hline & LI Volume & 1,43 & 0.125 & 0.29 & 0.051 & $-2.0 \pm 2.3$ & $9.3 \pm 30.1$ \\
\hline Left PoC-PrChand & $\mathrm{FC}$ & 1,38 & 0.127 & 0.29 & 0.06 & $1.30 \pm 0.42$ & $1.51 \pm 0.50$ \\
\hline Right PoC-PrC $\mathrm{hand}_{\mathrm{H}}$ & $\mathrm{FC}$ & 1,38 & 0.045 & 0.13 & 0.102 & $1.12 \pm 0.43$ & $1.39 \pm 0.46$ \\
\hline PoC-PrChand & LI FC & 1,38 & 0.336 & 0.47 & 0.024 & $16.2 \pm 30.9$ & $9.1 \pm 27.7$ \\
\hline
\end{tabular}

Significant at ${ }^{\mathrm{a}} q<.10$.

Volume in $\mathrm{ml}, \mathrm{MD}$ in $\left(\times 10^{-4} \mathrm{~mm}^{2} / \mathrm{s}\right)$. 
medRxiv preprint doi: https://doi.org/10.1101/2021.07.16.21260584; this version posted July 20, 2021. The copyright holder for this preprint (which was not certified by peer review) is the author/funder, who has granted medRxiv a license to display the preprint in perpetuity. It is made available under a CC-BY-NC-ND 4.0 International license .

\section{Upper and lower pre and post-central volume and connectivity}

The results of the upper and lower pre and postcentral measures are shown in Supplementary Table 2. No significant group differences survived FDR correction. While they did not reach the level of significance, a small effect size of group was observed in LI PoClower volume in the direction of greater leftward laterality in the ASD relative to TC group (partial $\eta^{2}=.071$; Supplementary Figure 3). There were also medium effect sizes of group in MD of the right PoC$\mathrm{PrC}_{\text {upper }} \mathrm{u}$-fiber tract (partial $\eta^{2}=.152, \mathrm{ASD}>\mathrm{TC}$ ) and in $\mathrm{FC}$ of left PoC-PrC lower (partial $\eta^{2}=.129$; $\mathrm{ASD}<\mathrm{TC}$ ) and bilateral $\mathrm{PoC}-\mathrm{PrC}_{\text {upper }}$ (left: partial $\eta^{2}=.145$; right: partial $\eta^{2}=.126$; both showing $\mathrm{ASD}<\mathrm{TC})$.

\section{Correlations between hand knob measures and motor skills}

The results of the partial correlation analyses with the BMAT subscales are reported in Table 3. As BMAT Coordination scores were at ceiling for almost all TC participants, this measure was excluded from further analysis in the TC group. We observed several nominally significant associations in the ASD group, however, they did not survive FDR correction. Nonetheless these were medium effect sizes that have not been previously reported in the literature. These include positive correlations between LI PrC $\mathrm{C}_{\text {hand }}$ volume and Manual Dexterity scores, and between right $\mathrm{PoC}_{\text {hand }}$ volume and Coordination scores, and a negative correlation between LI PoC-PrChand $\mathrm{u}-$ fiber FA and Coordination scores, in the ASD group (Table 3). No associations were found between PoC-PrChand FC and motor skills measures or with the Strength and Flexibility subscale in either group.

Table 3. Partial correlation results between hand knob measures and BMAT subscales in the ASD and TC groups.

\begin{tabular}{|c|c|c|c|c|c|c|c|c|c|}
\hline & \multicolumn{3}{|c|}{ Manual dexterity } & \multicolumn{3}{|c|}{ Coordination } & \multicolumn{3}{|c|}{$\begin{array}{l}\text { Strength and } \\
\text { flexibility }\end{array}$} \\
\hline & Partial $r$ & $p$ & $q$ & Partial r & $p$ & $q$ & Partial r & $p$ & $q$ \\
\hline & \multicolumn{9}{|c|}{ ASD } \\
\hline Left $\operatorname{PrC}_{\text {hand }}$ volume & 0.123 & 0.575 & 1.00 & -0.026 & 0.905 & 0.99 & 0.079 & 0.719 & 0.88 \\
\hline Left $\mathrm{PoC}_{\text {hand }}$ volume & 0.198 & 0.364 & 0.86 & 0.256 & 0.239 & 0.86 & 0.144 & 0.514 & 0.88 \\
\hline Right $\operatorname{PrC}$ hand volume & -0.240 & 0.270 & 0.86 & -0.002 & 0.994 & 0.99 & 0.142 & 0.519 & 0.88 \\
\hline Right $\mathrm{PoC}_{\text {hand }}$ volume & 0.058 & 0.791 & 1.00 & 0.480 & $0.021^{\mathrm{a}}$ & 0.22 & 0.089 & 0.685 & 0.88 \\
\hline LI PrChand volume & 0.433 & $0.039^{\mathrm{a}}$ & 0.70 & 0.035 & 0.874 & 0.99 & -0.012 & 0.958 & 0.96 \\
\hline LI PoChand volume & 0.196 & 0.371 & 0.86 & -0.214 & 0.327 & 0.89 & 0.047 & 0.831 & 0.88 \\
\hline Left PoC-PrChand FA & -0.226 & 0.324 & 0.86 & -0.327 & 0.149 & 0.67 & -0.071 & 0.759 & 0.88 \\
\hline Left PoC-PrChand MD & -0.112 & 0.628 & 1.00 & 0.108 & 0.641 & 0.89 & 0.064 & 0.783 & 0.88 \\
\hline Left PoC-PrChand volume & 0.286 & 0.208 & 0.86 & 0.127 & 0.582 & 0.89 & 0.293 & 0.197 & 0.88 \\
\hline Right PoC-PrChand FA & -0.075 & 0.747 & 1.00 & 0.149 & 0.518 & 0.89 & -0.146 & 0.528 & 0.88 \\
\hline
\end{tabular}


medRxiv preprint doi: https://doi.org/10.1101/2021.07.16.21260584; this version posted July 20, 2021. The copyright holder for this preprint (which was not certified by peer review) is the author/funder, who has granted medRxiv a license to display the preprint in perpetuity. It is made available under a CC-BY-NC-ND 4.0 International license .

\begin{tabular}{|c|c|c|c|c|c|c|c|c|c|}
\hline Right PoC-PrChand $\mathrm{MD}$ & -0.038 & 0.870 & 1.00 & 0.012 & 0.959 & 0.99 & 0.128 & 0.580 & 0.88 \\
\hline Right PoC-PrChand volume & 0.201 & 0.381 & 0.86 & 0.362 & 0.107 & 0.64 & 0.188 & 0.415 & 0.88 \\
\hline LI PoC-PrChand FA & -0.103 & 0.656 & 1.00 & -0.489 & $0.024^{\mathrm{a}}$ & 0.22 & 0.118 & 0.611 & 0.88 \\
\hline LI PoC-PrChand MD & -0.094 & 0.684 & 1.00 & 0.145 & 0.529 & 0.89 & -0.105 & 0.649 & 0.88 \\
\hline LI PoC-PrChand volume & 0.281 & 0.218 & 0.86 & -0.153 & 0.508 & 0.89 & 0.225 & 0.327 & 0.88 \\
\hline Left PoC-PrChand FC & 0.001 & 0.997 & 1.00 & 0.124 & 0.623 & 0.89 & -0.073 & 0.772 & 0.88 \\
\hline Right PoC-PrChand $\mathrm{FC}$ & -0.022 & 0.930 & 1.00 & 0.081 & 0.749 & 0.96 & -0.109 & 0.666 & 0.88 \\
\hline LI PoC-PrChand FC & 0.011 & 0.965 & 1.00 & 0.126 & 0.619 & 0.89 & 0.084 & 0.741 & 0.88 \\
\hline & \multicolumn{9}{|c|}{$\mathrm{TC}$} \\
\hline Left $\operatorname{PrC}$ hand volume & 0.088 & 0.688 & 0.83 & -- & -- & -- & 0.072 & 0.743 & 0.86 \\
\hline Left $\mathrm{PoC}_{\text {hand }}$ volume & 0.410 & 0.052 & 0.43 & -- & -- & -- & 0.127 & 0.565 & 0.86 \\
\hline Right $\mathrm{PrC}_{\text {hand }}$ volume & 0.395 & 0.062 & 0.43 & -- & -- & -- & 0.039 & 0.860 & 0.86 \\
\hline Right $\mathrm{PoC}_{\text {hand }}$ volume & 0.329 & 0.125 & 0.43 & -- & -- & -- & 0.170 & 0.439 & 0.86 \\
\hline LI PrChand volume & -0.298 & 0.167 & 0.43 & -- & -- & -- & -0.054 & 0.808 & 0.86 \\
\hline LI PoChand volume & -0.066 & 0.766 & 0.86 & -- & -- & -- & -0.094 & 0.670 & 0.86 \\
\hline Left PoC-PrC $\mathrm{Chand}_{\mathrm{FA}}$ & -0.226 & 0.572 & 0.79 & -- & -- & -- & -0.071 & 0.723 & 0.86 \\
\hline Left PoC-PrChand MD & -0.112 & 0.901 & 0.90 & -- & -- & -- & 0.064 & 0.298 & 0.86 \\
\hline Left PoC-PrChand volume & 0.286 & 0.453 & 0.79 & -- & -- & -- & 0.293 & 0.241 & 0.86 \\
\hline Right PoC-PrChand FA & -0.075 & 0.157 & 0.43 & -- & -- & -- & -0.146 & 0.171 & 0.86 \\
\hline Right PoC-PrChand $\mathrm{MD}$ & -0.038 & 0.883 & 0.90 & -- & -- & -- & 0.128 & 0.795 & 0.86 \\
\hline Right PoC-PrChand volume & 0.201 & 0.502 & 0.79 & -- & -- & -- & 0.188 & 0.682 & 0.86 \\
\hline LI PoC-PrChand FA & -0.103 & 0.142 & 0.43 & -- & -- & -- & 0.118 & 0.418 & 0.86 \\
\hline LI PoC-PrChand MD & -0.094 & 0.565 & 0.79 & -- & -- & -- & -0.105 & 0.237 & 0.86 \\
\hline LI PoC-PrChand volume & 0.281 & 0.636 & 0.82 & -- & -- & -- & 0.225 & 0.219 & 0.86 \\
\hline Left PoC-PrC $\mathrm{hand}_{\mathrm{FC}}$ & -0.149 & 0.520 & 0.79 & -- & -- & -- & -0.046 & 0.844 & 0.86 \\
\hline Right PoC-PrChand $\mathrm{FC}$ & 0.172 & 0.456 & 0.79 & -- & -- & -- & -0.108 & 0.641 & 0.86 \\
\hline LI PoC-PrC $\mathrm{Chand}_{\text {FC }}$ & -0.376 & 0.093 & 0.43 & -- & -- & -- & 0.068 & 0.770 & 0.86 \\
\hline
\end{tabular}

${ }^{\text {a }}$ Findings with $p<.05$ uncorrected, and medium effect sizes.

${ }^{\mathrm{b}}$ BMAT Coordination scores were at ceiling for almost all TC participants and was therefore excluded from analyses. 
medRxiv preprint doi: https://doi.org/10.1101/2021.07.16.21260584; this version posted July 20, 2021. The copyright holder for this preprint (which was not certified by peer review) is the author/funder, who has granted medRxiv a license to display the preprint in perpetuity. It is made available under a CC-BY-NC-ND 4.0 International license .

\section{Correlations between hand knob measures and autism symptoms}

The results of the partial correlation analyses with the ADOS-2 sub-scores are reported in Table 4. After FDR correction, right $\mathrm{PoC}-\mathrm{PrC}_{\text {hand }} \mathrm{u}$-fiber volume was negatively correlated with the Comparison score in the ASD group (Figure 2A). Associations with medium to large effect sizes were observed between right PoC-PrChand $\mathrm{u}$-fiber volume and $\mathrm{LI}$ PoC-PrChand $\mathrm{MD}$ with the RRB sub-score (both showed a negative relationship), and between LI PoC-PrChand $\mathrm{u}$-fiber FA and the Comparison score (positive relationship), but did not survive FDR correction (see Table 4).
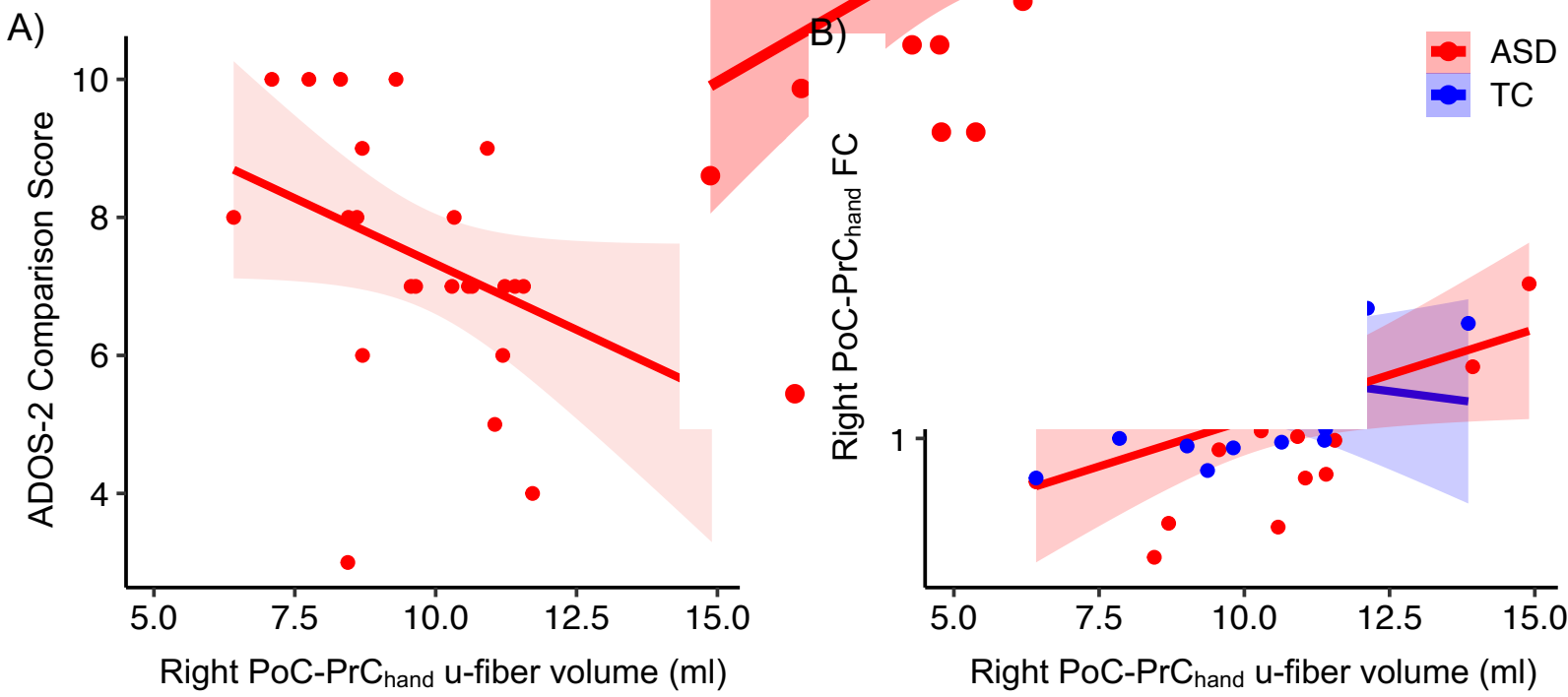

Figure 2. Scatterplots show A) a negative relationship between right $\mathrm{PoC}-\mathrm{PrC}_{\text {hand }} \mathrm{u}$-fiber tract volume and current levels of autism severity as measured by the ADOS-2 Comparison Score (partial $r=-.584, q=.09$ ), and B) a positive relationship between right $\mathrm{PoC}$-PrChand $\mathrm{U}$-fiber tract volume and right $\mathrm{PoC}-\mathrm{PrC}_{\text {hand }} \mathrm{FC}$, in the ASD group (partial $r=.647, q=.06$ ). Shaded areas in the scatterplots represent $95 \%$ confidence intervals.

\section{Correlations between PoC-PrChand structural and functional connectivity}

After FDR correction, we found a significant positive association between right PoC$\mathrm{PrC}_{\text {hand }} \mathrm{u}$-fiber volume and right $\mathrm{PoC}-\mathrm{PrC}_{\text {hand }} \mathrm{FC}$ in the $\mathrm{ASD}$ group only (partial $r(16)=.647$, $p=.007, q=.06$; Figure 2B). No associations between structural and functional connectivity measures were observed in the TC group. 
Table 4. Partial correlation results between hand knob measures and ADOS-2 sub-scores in the ASD group.

\begin{tabular}{|c|c|c|c|c|c|c|c|c|c|}
\hline & \multicolumn{3}{|c|}{ Social Affect } & \multicolumn{3}{|c|}{ RRB } & \multicolumn{3}{|c|}{ Comparison Score } \\
\hline & Partial $r$ & $p$ & $q$ & Partial $r$ & $p$ & $q$ & Partial $r$ & $p$ & $q$ \\
\hline Left $\operatorname{PrC}_{\text {hand }}$ volume & 0.191 & 0.382 & 0.74 & 0.022 & 0.921 & 0.92 & 0.076 & 0.730 & 0.88 \\
\hline Left $\mathrm{PoC}_{\text {hand }}$ volume & 0.087 & 0.692 & 0.78 & 0.083 & 0.705 & 0.92 & 0.046 & 0.835 & 0.88 \\
\hline Right $\operatorname{PrC}_{\text {hand }}$ volume & 0.201 & 0.357 & 0.74 & -0.197 & 0.367 & 0.66 & -0.066 & 0.766 & 0.88 \\
\hline Right $\mathrm{PoC}_{\text {hand }}$ volume & -0.151 & 0.492 & 0.74 & -0.165 & 0.452 & 0.74 & -0.308 & 0.152 & 0.46 \\
\hline LI PrC $\mathrm{C}_{\text {hand }}$ volume & 0.115 & 0.601 & 0.77 & 0.336 & 0.117 & 0.42 & 0.263 & 0.225 & 0.46 \\
\hline LI PoChand volume & 0.249 & 0.251 & 0.74 & 0.229 & 0.294 & 0.66 & 0.295 & 0.172 & 0.46 \\
\hline Left PoC-PrC hand $_{\text {FA }}$ & 0.224 & 0.330 & 0.74 & 0.035 & 0.880 & 0.92 & 0.243 & 0.289 & 0.52 \\
\hline Left PoC-PrChand MD & 0.024 & 0.917 & 0.94 & 0.040 & 0.863 & 0.92 & 0.084 & 0.718 & 0.88 \\
\hline Left PoC-PrChand volume & 0.198 & 0.390 & 0.74 & -0.214 & 0.352 & 0.66 & -0.028 & 0.903 & 0.90 \\
\hline Right PoC-PrC $\mathrm{Chand}_{\mathrm{FA}}$ & -0.143 & 0.537 & 0.74 & -0.309 & 0.173 & 0.52 & -0.279 & 0.221 & 0.46 \\
\hline Right PoC-PrChand $\mathrm{MD}$ & 0.158 & 0.494 & 0.74 & 0.356 & 0.113 & 0.42 & 0.345 & 0.125 & 0.46 \\
\hline Right PoC-PrChand volume & -0.268 & 0.240 & 0.74 & -0.505 & 0.019 & 0.17 & -0.584 & 0.005 & $0.09^{\mathrm{a}}$ \\
\hline LI PoC-PrC $\mathrm{Chand}_{\text {FA }}$ & 0.289 & 0.204 & 0.74 & 0.425 & 0.055 & 0.33 & 0.493 & 0.023 & 0.21 \\
\hline LI PoC-PrChand MD & -0.108 & 0.641 & 0.77 & -0.540 & 0.012 & 0.17 & -0.372 & 0.097 & 0.46 \\
\hline LI PoC-PrChand volume & 0.222 & 0.335 & 0.74 & 0.223 & 0.332 & 0.66 & 0.274 & 0.229 & 0.46 \\
\hline Left PoC-PrChand FC & -0.019 & 0.939 & 0.94 & 0.052 & 0.837 & 0.92 & 0.064 & 0.802 & 0.88 \\
\hline Right PoC-PrChand $\mathrm{FC}$ & 0.199 & 0.428 & 0.74 & -0.049 & 0.848 & 0.92 & 0.119 & 0.637 & 0.88 \\
\hline LI PoC-PrChand FC & -0.239 & 0.339 & 0.74 & 0.149 & 0.556 & 0.83 & 0.058 & 0.818 & 0.88 \\
\hline
\end{tabular}

a Significant at $q<.10$. 
medRxiv preprint doi: https://doi.org/10.1101/2021.07.16.21260584; this version posted July 20, 2021. The copyright holder for this preprint

(which was not certified by peer review) is the author/funder, who has granted medRxiv a license to display the preprint in perpetuity.

It is made available under a CC-BY-NC-ND 4.0 International license .

\section{Discussion}

To our knowledge, this is the first study to combine morphological, connectivity and asymmetry measures of the hand knob area in adults with ASD. Consistent with our hypotheses, we found that: 1) typical leftward asymmetry in $\mathrm{PrC}_{\text {hand }}$ and $\mathrm{PoC}_{\text {hand }}$ volume was reduced in adults with ASD, 2) for $\mathrm{PrC}_{\text {hand, }}$, this reduced asymmetry was driven by increased right $\mathrm{PrC}_{\text {hand }}$ volume in the ASD group, and 3) PoC-PrChand structural connectivity was altered in ASD, with evidence of compromised microstructure (increased MD) in the right u-fibers. Together, our findings suggest a less lateralized neural circuitry as well as less support for efficient communication between sensory and motor regions of the hand knob area in middle-aged adults with ASD. While no associations between the hand knob measures and motor skills survived FDR correction, a negative relationship was observed between right $\mathrm{PoC}-\mathrm{PrC}_{\text {hand }} \mathrm{u}$-fiber volume and autism symptom severity in the ASD group. This may indicate a compensatory role of the $\mathrm{PoC}-\mathrm{PrC}_{\mathrm{hand}} \mathrm{u}$-fibers in modulating motor behaviors associated with ASD.

\section{Reduced asymmetry of $\operatorname{PrC}_{\text {hand }}$ and $P o C_{\text {hand }}$ in $A S D$}

In typical individuals, handedness is associated with a deeper central sulcus, particularly in its dorsal portion, in the hemisphere contralateral to the dominant hand (Amunts et al., 1996, 2000; Cykowski et al., 2008; Klöppel et al., 2010; Sun et al., 2012). A deeper sulcus would presumably indicate an increased dorsal pre and postcentral cortical volume. Indeed, in this righthanded sample, we found that $\mathrm{PrC}_{h a n d}$ and $\mathrm{PoC}_{\text {hand }}$ volume were significantly left-lateralized in the TC group and this effect was primarily driven by SA rather than CT, consistent with previous findings. Higher rates of mixed or left-handedness reported in individuals with ASD, together estimated to be $\sim 42 \%$ when adjusting for publication bias (Markou et al., 2017) compared with $\sim 13 \%$ in the general population (Partida et al., 2020), would be expected to lead to reduced leftward or increased rightward volume laterality in the ASD population (i.e., consistent with our observed group effects). In our study, however, left-handed individuals were excluded and the diagnostic groups were matched on degree of handedness (i.e., EHI scores), to avoid skewing of group findings. As an added safeguard, we performed additional analyses restricted to the strongly righthanded individuals (excluding individuals with $\mathrm{EHI}<80$ ). The group effects on hand knob volume and volume laterality, discussed below, had medium to large effect sizes in this more restricted sample, confirming that these results are not driven by the weakly right-handed individuals.

Our finding of increased right $\mathrm{PrC}_{\text {hand }}$ volume in middle-aged and older adults with ASD is consistent with previous reports of increased grey matter density in right pericentral cortex at the level of the hand knob in younger adults with ASD (DeRamus \& Kana, 2015; Ecker et al., 2012). Our findings of reduced asymmetry in $\mathrm{PrC}_{\text {hand }}$ and $\mathrm{PoC}_{\text {hand }}$ volumes are also consistent with previous unilateral findings of increased right and/or decreased left grey matter density and volume in the pre- and postcentral gyri in ASD (Cauda et al., 2011; DeRamus \& Kana, 2015; Ecker et al., 2012; Mahajan et al., 2016; Nickl-Jockschat et al., 2012; Säisänen et al., 2019), which may be interpreted in the context of reduced asymmetry. To our knowledge, morphological asymmetry has only been examined in a few studies on ASD (Floris, Lai, et al., 2016; Herbert et al., 2005; Postema et al., 2019). While none of these detected group differences in the precentral gyrus, Herbert et al. (2005) found reduced asymmetry in postcentral gyral volume in children with ASD. 
medRxiv preprint doi: https://doi.org/10.1101/2021.07.16.21260584; this version posted July 20, 2021. The copyright holder for this preprint (which was not certified by peer review) is the author/funder, who has granted medRxiv a license to display the preprint in perpetuity. It is made available under a CC-BY-NC-ND 4.0 International license .

As with language lateralization, functional lateralization of motor systems is widely viewed to be advantageous for neural communication by optimizing conduction time and wiring capacity (Karolis et al., 2019). Reduced asymmetry in morphology of the hand knob area suggests less hemispheric specialization for efficient neural motor processing of hand motor/premotor function in middle-aged adults with ASD. It may also reflect an altered strategy for motor processing over time, e.g., an increased reliance on specialized right hemisphere motor functions to correct and update ongoing actions (Mutha et al., 2012), in individuals with ASD. Indeed, increased recruitment of right pericentral and premotor areas during motor learning has been reported in young adults with ASD (Müller et al., 2004). Additionally, in healthy aging, a shift towards reduced functional hemispheric asymmetry including in the sensorimotor domain has been hypothesized and presumed to reflect compensatory changes (Cabeza, 2002).

By delineating the hand knob regions, we were able to perform analyses on different subparcels of the pre and postcentral gyri. We observed significant leftward volume asymmetry only in $\mathrm{PrC}_{\text {hand }}$ and $\mathrm{PoC}_{\text {hand, }}$ and not in the upper and lower sub-parcels in the TC group indicating that this asymmetry is largely specific to the hand knob region. This is consistent with previous morphometric studies in right-handed individuals (Amunts et al., 1996, 2000; Cykowski et al., 2008; S Rose et al., 2012). Thus, future studies investigating morphological asymmetry of the pre and postcentral gyri should take into consideration the likelihood of varying degrees (and possibly direction) of asymmetry along the dorso-ventral axis.

Decreased PoC-PrChand -fiber connectivity in ASD

Our findings also suggest altered microstructure of right $\mathrm{PoC}-\mathrm{PrC} \mathrm{C}_{\text {hand }} \mathrm{u}$-fibers and a similar trend in left PoC-PrChand $\mathrm{u}$-fibers. Increased MD in the ASD group, which may reflect axonal degeneration or possibly inflammation (Alexander et al., 2007), is in line with a previous report of increased MD (and reduced FA) of $\mathrm{PoC}-\mathrm{PrC}_{\text {hand }} \mathrm{u}$-fibers bilaterally in younger adults with ASD (Thompson et al., 2017).

This potential reduction in structural connectivity between somatosensory $\left(\mathrm{PoC}_{\mathrm{hand}}\right)$ and motor $\left(\mathrm{PrC}_{\mathrm{hand}}\right)$ hand knob areas in $\mathrm{ASD}$ could have important functional implications. Diffusion tractography does not permit the distinction between afferent and efferent connections but bidirectional connections between primary somatosensory and primary motor cortex have been demonstrated using axonal tracing in mouse (Matyas et al., 2010), and these could have distinct functional relevance. Feedforward $\mathrm{PoC}_{\text {hand }}-\mathrm{PrC}_{\text {hand }}$ connections are likely to play an important role in learning new motor skills based on evidence in monkeys (Pavlides et al., 1993) and humans (Kumar et al., 2019; Veldman et al., 2018). Therefore, compromised microstructure of these ufibers may contribute to abnormal patterns of motor learning in ASD (de Moraes et al., 2017). These u-fibers are likely also important for fine motor skills and impairment in these connections can affect grasp stability (Shinoura et al., 2005). Indeed, atypical grasp kinematics have been reported in adults with ASD (Cook et al., 2013). Future studies should directly test whether these $\mathrm{u}$-fibers are linked to aspects of motor learning and fine motor control (e.g., handwriting difficulties (Grace et al., 2017)) in ASD, particularly in early childhood when development of these skills is most critical. Reciprocal $\mathrm{PrC}_{\text {hand }}-\mathrm{PoC}_{\text {hand }}$ connections may exert top-down influences on somatosensory cortex (e.g., M2 to S1 (Manita et al., 2015)) and could contribute to atypical sensory perception in ASD (Manita et al., 2015; Umeda et al., 2019).

One study found that FA of superficial white matter underlying the right pre and postcentral gyri positively correlated with finger tapping performance and that declining FA mediated age- 
medRxiv preprint doi: https://doi.org/10.1101/2021.07.16.21260584; this version posted July 20, 2021. The copyright holder for this preprint

(which was not certified by peer review) is the author/funder, who has granted medRxiv a license to display the preprint in perpetuity.

It is made available under a CC-BY-NC-ND 4.0 International license .

related decline in fine motor performance in healthy adults aged 18-86 years (Nazeri et al., 2015). These u-fibers are thus particularly important for maintaining fine motor skills during aging.

\section{Correlations with motor skills}

No significant correlations were found between hand knob measures and motor skills in either diagnostic group after correction for multiple comparisons. There were, however, correlations of medium effect size in the ASD group of hand knob measures with the Manual Dexterity and Coordination subscales, but not Strength and Flexibility. As expected, greater leftlateralized $\mathrm{PrC}_{\text {hand }}$ volume was linked to better manual dexterity skills, however, increased right $\mathrm{PoC}_{\text {hand }}$ volume and greater right-lateralized microstructural integrity (as measured by FA) of PoC$\mathrm{PrC}_{\text {hand }} \mathrm{u}$-fibers tended to associate with better motor coordination skills in adults with ASD. Interestingly, Thompson and colleagues observed associations between manual dexterity skills (on a pegboard task) and right hemisphere u-fiber measures in their adult ASD sample, which contrasted with the left hemisphere u-fiber associations observed in their TC group (Thompson et al., 2017). Atypical right $\mathrm{PoC}_{\text {hand }}$ and u-fiber correlations with motor performance in adults with ASD could reflect an unusual reliance on on-line corrective sensorimotor processes in the right hemisphere.

\section{Correlations with autism symptom severity}

Greater right $\mathrm{PoC}-\mathrm{PrC}_{\text {hand }} \mathrm{u}$-fiber volume, reflecting more substantial structural connections, was significantly associated with lower severity of current autism symptoms (as measured by ADOS-2 Comparison Score) in middle-aged adults with ASD. While both RRB and Social Affect sub-scores showed a negative trend with right $\mathrm{PoC}-\mathrm{PrC}$ hand $\mathrm{u}$-fiber volume, only the correlation with RRB was significant prior to FDR correction. One hypothesis is that the right $u-$ fibers may be involved in individuals' self-regulation of motor behaviors associated with ASD, such as repetitive movements (e.g., hand flapping, finger flicking). Furthermore, the observed positive correlation between right $\mathrm{PoC}-\mathrm{PrC}$ hand $\mathrm{u}$-fiber volume and $\mathrm{FC}$ suggests that activitydependent mechanisms are linked to changes in u-fiber tract volume and are behaviorally relevant in adults with ASD (Sampaio-Baptista \& Johansen-Berg, 2017).

\section{Limitations}

The small sample size of our study is one limiting factor. While our hand knob u-fiber findings replicates (and extends) a previous ASD study (Thompson et al., 2017), our novel laterality and morphology findings of the hand knob area in adults with ASD will require confirmation in larger samples. In particular, it is not known whether these findings are generalizable to left-handed adults with ASD. Lack of significant associations between the hand knob u-fiber measures and motor skills in the TC group may be due to a limited range of scores on the BMAT Short Form. Assessments which better capture the full range of motor function should be used in future studies. As intra-subject variability of motor task performance increases with aging (Hunter et al., 2016), repeat measurements may increase the reliability of motor measures in middle-aged and older adults. 


\section{Conclusions}

Our multi-modal MRI findings suggest that there is reduced morphological asymmetry and compromised PoC-PrC u-fibers of the hand knob area in middle-aged adults with ASD. Our findings may relate to atypical functional asymmetries found in children and young adults with ASD (Cardinale et al., 2013; Floris, Barber, et al., 2016), but could additionally reflect a compensatory functional overreliance on right hemisphere motor circuits over time. The right PoC$\mathrm{PrC}_{\text {hand }} \mathrm{u}$-fibers were linked to their corresponding FC and may underlie compensatory selfregulation of unwanted motor behaviors seen in ASD. Given that manual motor function typically begins to decline in middle-age (Hoogendam et al., 2014; Ranganathan et al., 2001) and can significantly impact quality of life, longitudinal follow-up is needed.

\section{Acknowledgements}

This study was supported by the National Institutes of Health R01 MH103494. The authors would like to thank all of the study participants. 
medRxiv preprint doi: https://doi.org/10.1101/2021.07.16.21260584; this version posted July 20, 2021. The copyright holder for this preprint

(which was not certified by peer review) is the author/funder, who has granted medRxiv a license to display the preprint in perpetuity.

It is made available under a CC-BY-NC-ND 4.0 International license .

\section{References}

Alexander, A. L., Lee, J. E., Lazar, M., \& Field, A. S. (2007). Diffusion tensor imaging of the brain. Neurotherapeutics: The Journal of the American Society for Experimental NeuroTherapeutics, 4(3), 316-329. https://doi.org/10.1016/j.nurt.2007.05.011

American Psychiatric Association (Ed.). (2013). Diagnostic and Statistical Manual of Mental Disorders (DSM-5) (5th ed.). American Psychiatric Association Publishing.

Amunts, K., Jäncke, L., Mohlberg, H., Steinmetz, H., \& Zilles, K. (2000). Interhemispheric asymmetry of the human motor cortex related to handedness and gender. Neuropsychologia, 38(3), 304-312. https://doi.org/10.1016/S0028-3932(99)00075-5

Amunts, K., Schlaug, G., Schleicher, A., Steinmetz, H., Dabringhaus, A., Roland, P. E., \& Zilles, K. (1996). Asymmetry in the human motor cortex and handedness. NeuroImage, 4(3), 216222. https://doi.org/10.1006/nimg.1996.0073

Andersson, J. L. R., Graham, M. S., Drobnjak, I., Zhang, H., Filippini, N., \& Bastiani, M. (2017). Towards a comprehensive framework for movement and distortion correction of diffusion MR images: Within volume movement. NeuroImage, 152(February), 450-466. https://doi.org/10.1016/j.neuroimage.2017.02.085

Andersson, J. L. R., Graham, M. S., Zsoldos, E., \& Sotiropoulos, S. N. (2016). Incorporating outlier detection and replacement into a non-parametric framework for movement and distortion correction of diffusion MR images. NeuroImage, 141, 556-572. https://doi.org/10.1016/j.neuroimage.2016.06.058

Andersson, J. L. R., Skare, S., \& Ashburner, J. (2003). How to correct susceptibility distortions in spin-echo echo-planar images: Application to diffusion tensor imaging. NeuroImage, 20(2), 870-888. https://doi.org/10.1016/S1053-8119(03)00336-7

Andersson, J. L. R., \& Sotiropoulos, S. N. (2016). An integrated approach to correction for offresonance effects and subject movement in diffusion MR imaging. NeuroImage, 125, 10631078. https://doi.org/10.1016/j.neuroimage.2015.10.019

Benjamini, Y., \& Hochberg, Y. (1995). Benjamini Y, Hochberg Y. Controlling the false discovery rate: a practical and powerful approach to multiple testing. Journal of the Royal Statistical Society B, 57(1), 289-300. https://doi.org/10.2307/2346101

Bhat, A. N. (2020). Is motor impairment in autism spectrum disorder distinct from developmental coordination disorder? A report from the SPARK study. Physical Therapy, 100(4), 633-644.

Bremer, E., \& Cairney, J. (2018). The Interrelationship Between Motor Coordination and Adaptive Behavior in Children With Autism Spectrum Disorder. Frontiers in Psychology, 9(November), 1-7. https://doi.org/10.3389/fpsyg.2018.02350

Bruininks, R., \& Bruininks, B. (2012). Bruininks Motor Abilities Test. Pearson.

Cabeza, R. (2002). Hemispheric asymmetry reduction in older adults: The HAROLD model. Psychology and Aging, 17(1), 85-100. https://doi.org/10.1037/0882-7974.17.1.85

Cardinale, R. C., Shih, P., Fishman, I., Ford, L. M., \& Müller, R. A. (2013). Pervasive rightward asymmetry shifts of functional networks in autism spectrum disorder. JAMA Psychiatry, 70(9), 975-982. https://doi.org/10.1001/jamapsychiatry.2013.382

Catani, M. (2017). A little man of some importance. Brain, 140(11), 3055-3061. https://doi.org/10.1093/brain/awx270

Catani, M., Dell'acqua, F., Vergani, F., Malik, F., Hodge, H., Roy, P., Valabregue, R., \& 
medRxiv preprint doi: https://doi.org/10.1101/2021.07.16.21260584; this version posted July 20, 2021. The copyright holder for this preprint

(which was not certified by peer review) is the author/funder, who has granted medRxiv a license to display the preprint in perpetuity. It is made available under a CC-BY-NC-ND 4.0 International license .

Thiebaut de Schotten, M. (2012). Short frontal lobe connections of the human brain. Cortex; a Journal Devoted to the Study of the Nervous System and Behavior, 48(2), 273291. https://doi.org/10.1016/j.cortex.2011.12.001

Cauda, F., Geda, E., Sacco, K., D’Agata, F., Duca, S., Geminiani, G., \& Keller, R. (2011). Grey matter abnormality in autism spectrum disorder: An activation likelihood estimation metaanalysis study. Journal of Neurology, Neurosurgery and Psychiatry, 82(12), 1304-1313. https://doi.org/10.1136/jnnp.2010.239111

Caulo, M., Briganti, C., Mattei, P. A., Perfetti, B., Ferretti, A., Romani, G. L., Tartaro, A., \& Colosimo, C. (2007). New morphologic variants of the hand motor cortex as seen with MR imaging in a large study population. American Journal of Neuroradiology, 28(8), 14801485. https://doi.org/10.3174/ajnr.A0597

Cook, J. L., Blakemore, S. J., \& Press, C. (2013). Atypical basic movement kinematics in autism spectrum conditions. Brain, 136(9), 2816-2824. https://doi.org/10.1093/brain/awt208

Croen, L. A., Zerbo, O., Qian, Y., Massolo, M. L., Rich, S., Sidney, S., \& Kripke, C. (2015). The health status of adults on the autism spectrum. Autism, 19(7), 814-823. https://doi.org/10.1177/1362361315577517

Curreri, C., Trevisan, C., Carrer, P., Facchini, S., Giantin, V., Maggi, S., Noale, M., De Rui, M., Perissinotto, E., Zambon, S., Crepaldi, G., Manzato, E., \& Sergi, G. (2018). Difficulties with Fine Motor Skills and Cognitive Impairment in an Elderly Population: The Progetto Veneto Anziani. Journal of the American Geriatrics Society, 66(2), 350-356. https://doi.org/10.1111/jgs.15209

Cykowski, M. D., Coulon, O., Kochunov, P. V, Amunts, K., Lancaster, J. L., Laird, A. R., Glahn, C., \& Fox, P. T. (2008). The Central Sulcus : an Observer- Independent Characterization of Sulcal Landmarks and Depth Asymmetry. Cerebral Cortex, 18(September 2008), 1999-2009. https://doi.org/10.1093/cercor/bhm224

Dale, A. M., Fischl, B., \& Sereno, M. I. (1999). Cortical Surface-Based Analysis I: Segmentation and Surface Reconstruction. NeuroImage, 9, 179-194. https://doi.org/10.1006/nimg.1998.0395

Dassonville, P., Zhu, X.-H., Ugurbil, K., Kim, S.-G., \& Ashe, J. (1997). Functional activation in motor cortex reflects the direction and the degree of handedness. Proc Natl Acad Sci, 94, 14015-14018.

de Moraes, Í. A. P., Massetti, T., Crocetta, T. B., da Silva, T. D., de Menezes, L. D. C., de Mello Monteiro, C. B., \& Magalhães, F. H. (2017). Motor learning characterization in people with autism spectrum disorder: A systematic review. Dementia e Neuropsychologia, 11(3), 276286. https://doi.org/10.1590/1980-57642016dn11-030010

DeRamus, T. P., \& Kana, R. K. (2015). Anatomical likelihood estimation meta-analysis of grey and white matter anomalies in autism spectrum disorders. NeuroImage: Clinical, 7, 525536. https://doi.org/10.1016/j.nicl.2014.11.004

Desikan, R. S., Ségonne, F., Fischl, B., Quinn, B. T., Dickerson, B. C., Blacker, D., Buckner, R. L., Dale, A. M., Maguire, R. P., Hyman, B. T., Albert, M. S., \& Killiany, R. J. (2006). An automated labeling system for subdividing the human cerebral cortex on MRI scans into gyral based regions of interest. NeuroImage, 31, 968-980.

https://doi.org/10.1016/j.neuroimage.2006.01.021

Dhollander, T., Mito, R., Raffelt, D., \& Connelly, A. (2019). Improved white matter response function estimation for 3-tissue constrained spherical deconvolution. Proc. Intl. Soc. Mag. Reson. Med, May 11-16, 555. 
medRxiv preprint doi: https://doi.org/10.1101/2021.07.16.21260584; this version posted July 20, 2021. The copyright holder for this preprint

(which was not certified by peer review) is the author/funder, who has granted medRxiv a license to display the preprint in perpetuity. It is made available under a CC-BY-NC-ND 4.0 International license .

Ecker, C., Suckling, J., Deoni, S. C., Lombardo, M. V, Bullmore, E. T., Baron-Cohen, S., Catani, M., Jezzard, P., Barnes, A., Bailey, A. J., Williams, S. C., \& Murphy, D. G. M. (2012).

Brain Anatomy and Its Relationship to Behavior in Adults With Autism Spectrum Disorder. Archives of General Psychiatry, 69(2), 195-209.

Fischl, B., Sereno, M. I., \& Dale, A. M. (1999). Cortical Surface-Based Analysis II: Inflation, Flattening, and a Surface-Based Coordinate System. NeuroImage, 9, 195-207.

Floris, D. L., Barber, A. D., Nebel, M. B., Martinelli, M., Lai, M. C., Crocetti, D., Baron-Cohen, S., Suckling, J., Pekar, J. J., \& Mostofsky, S. H. (2016). Atypical lateralization of motor circuit functional connectivity in children with autism is associated with motor deficits. Molecular Autism, 7(35), 1-14. https://doi.org/10.1186/s13229-016-0096-6

Floris, D. L., Lai, M., Auer, T., Lombardo, M. V, Ecker, C., Chakrabarti, B., Wheelwright, S. J., Bullmore, E. T., \& Murphy, D. G. M. (2016). Atypically Rightward Cerebral Asymmetry in Male Adults With Autism Stratifies Individuals With and Without Language Delay. Human Brain Mapping, 253, 230-253. https://doi.org/10.1002/hbm.23023

Fortin, J. P., Parker, D., Tunç, B., Watanabe, T., Elliott, M. A., Ruparel, K., Roalf, D. R., Satterthwaite, T. D., Gur, R. C., Gur, R. E., Schultz, R. T., Verma, R., \& Shinohara, R. T. (2017). Harmonization of multi-site diffusion tensor imaging data. NeuroImage, 161(August), 149-170. https://doi.org/10.1016/j.neuroimage.2017.08.047

Fuentes, C. T., Mostofsky, S. H., \& Bastian, A. J. (2009). Children with autism show specific handwriting impairments. Neurology, 73(19), 1532-1537. https://doi.org/10.1212/WNL.0b013e3181c0d48c

Fuentes, C. T., Mostofsky, S. H., \& Krieger, K. (2010). Perceptual reasoning predicts handwriting impairments in adolescents with autism. Neurology, 75, 1825-1829.

Gass, A., Szabo, K., Behrens, S., Rossmanith, C., \& Hennerici, M. (2001). A diffusion-weighted MRI study of acute ischemic distal arm paresis. Neurology, 57, 1589-1594. https://doi.org/10.1212/WNL.59.4.650

Geyer, S., Ledberg, A., Schleicher, A., Kinomura, S., Schormann, T., Bürgel, U., Klingberg, T., Larsson, J., Zilles, K., \& Roland, P. E. (1996). Two different areas within the primary motor cortex of man. Letters To Nature, 382(29), 805-807.

Geyer, S., Matelli, M., Luppino, G., \& Zilles, K. (2000). Functional neuroanatomy of the primate isocortical motor system. Anatomy and Embryology, 202, 443-474. papers://11220527b037-458d-8d7a-1b9030c00b53/Paper/p4746\%5Cnpapers://11220527-b037-458d-8d7a1b9030c00b53/Paper/p4009

Gowen, E., \& Hamilton, A. (2013). Motor abilities in autism: A review using a computational context. Journal of Autism and Developmental Disorders, 43(2), 323-344. https://doi.org/10.1007/s10803-012-1574-0

Grace, N., Enticott, P. G., Johnson, B. P., \& Rinehart, N. J. (2017). Do Handwriting Difficulties Correlate with Core Symptomology, Motor Proficiency and Attentional Behaviours? Journal of Autism and Developmental Disorders, 47(4), 1006-1017. https://doi.org/10.1007/s10803-016-3019-7

Green, D., Charman, T., Pickles, A., Chandler, S., Loucas, T., Simonoff, E., \& Baird, G. (2009). Impairment in movement skills of children with autistic spectrum disorders. Developmental Medicine and Child Neurology, 51, 311-316. https://doi.org/10.1111/j.14698749.2008.03242.x

Greimel, E., Nehrkorn, B., Schulte-Rüther, M., Fink, G. R., Nickl-Jockschat, T., HerpertzDahlmann, B., Konrad, K., \& Eickhoff, S. B. (2013). Changes in grey matter development 
medRxiv preprint doi: https://doi.org/10.1101/2021.07.16.21260584; this version posted July 20, 2021. The copyright holder for this preprint

(which was not certified by peer review) is the author/funder, who has granted medRxiv a license to display the preprint in perpetuity.

It is made available under a CC-BY-NC-ND 4.0 International license .

in autism spectrum disorder. Brain Structure and Function, 218(4), 929-942.

https://doi.org/10.1007/s00429-012-0439-9

Greve, D. N., \& Fischl, B. (2009). Accurate and robust brain image alignment using boundarybased registration. NeuroImage, 48(1), 63-72.

https://doi.org/10.1016/j.neuroimage.2009.06.060

Guevara, M., Román, C., Houenou, J., Duclap, D., Poupon, C., Mangin, J. F., \& Guevara, P. (2017). Reproducibility of superficial white matter tracts using diffusion-weighted imaging tractography. NeuroImage, 147(November 2016), 703-725. https://doi.org/10.1016/j.neuroimage.2016.11.066

Hallett, M. (2007). Transcranial Magnetic Stimulation: A Primer. Neuron, 55(2), 187-199. https://doi.org/10.1016/j.neuron.2007.06.026

Herbert, M. R., Ziegler, D. A., Deutsch, C. K., O’Brien, L. M., Kennedy, D. N., Filipek, P. A., Bakardjiev, A. I., Hodgson, J., Takeoka, M., Makris, N., \& Caviness, V. S. (2005). Brain asymmetries in autism and developmental language disorder: A nested whole-brain analysis. Brain, 128(1), 213-226. https://doi.org/10.1093/brain/awh330

Hoogendam, Y. Y., van der Lijn, F., Vernooij, M. W., Hofman, A., Niessen, W. J., van der Lugt, A., Ikram, M. A., \& van der Geest, J. N. (2014). Older age relates to worsening of fine motor skills: A population based study of middle-aged and elderly persons. Frontiers in Aging Neuroscience, 6(SEP), 1-7. https://doi.org/10.3389/fnagi.2014.00259

Hunter, S. K., Pereira, H. M., \& Keenan, K. G. (2016). The aging neuromuscular system and motor performance. Journal of Applied Physiology, 121, 982-995.

https://doi.org/10.1152/japplphysiol.00475.2016

Iverson, J. M., Shic, F., Wall, C. A., Chawarska, K., Curtin, S., Estes, A., Gardner, J. M., Hutman, T., Landa, R. J., Levin, A. R., Libertus, K., Messinger, D. S., Nelson, C. A., Ozonoff, S., Sacrey, L. A. R., Sheperd, K., Stone, W. L., Tager-Flusberg, H. B., Wolff, J. J., ... Young, G. S. (2019). Early motor abilities in infants at heightened versus low risk for ASD: A Baby Siblings Research Consortium (BSRC) study. Journal of Abnormal Psychology, 128(1), 69-80. https://doi.org/10.1037/abn0000390

Jasmin, E., Couture, M., McKinley, P., Reid, G., Fombonne, E., \& Gisel, E. (2009). Sensorimotor and Daily Living Skills of Preschool Children with Autism Spectrum Disorders. Journal of Autism and Developmental Disorders, 39, 231-241. https://doi.org/10.1007/s10803-008-0617-z

Jeurissen, B., Tournier, J. D., Dhollander, T., Connelly, A., \& Sijbers, J. (2014). Multi-tissue constrained spherical deconvolution for improved analysis of multi-shell diffusion MRI data. NeuroImage, 103, 411-426. https://doi.org/10.1016/j.neuroimage.2014.07.061

Johnson, W. E., Li, C., \& Rabinovic, A. (2007). Adjusting batch effects in microarray expression data using empirical Bayes methods. Biostatistics, 8(1), 118-127. https://doi.org/10.1093/biostatistics/kxj037

Karolis, V. R., Corbetta, M., \& Thiebaut de Schotten, M. (2019). The architecture of functional lateralisation and its relationship to callosal connectivity in the human brain. Nature Communications, 10(1), 1-9. https://doi.org/10.1038/s41467-019-09344-1

Katz, S. (1983). Assessing self-maintenance: Activities of daily living, mobility, and instrumental activities of daily living. Journal of the American Geriatrics Society, 31(12), 721-727. https://doi.org/10.1111/j.1532-5415.1983.tb03391.x

Klöppel, S., Mangin, J.-F., Vongerichten, A., Frackowiak, R. S. J., \& Siebner, H. R. (2010). Nurture versus Nature : Long-Term Impact of Forced Right-Handedness on Structure of 
medRxiv preprint doi: https://doi.org/10.1101/2021.07.16.21260584; this version posted July 20, 2021. The copyright holder for this preprint

(which was not certified by peer review) is the author/funder, who has granted medRxiv a license to display the preprint in perpetuity. It is made available under a CC-BY-NC-ND 4.0 International license .

Pericentral Cortex. Journal of Neuroscience, 30(9), 3271-3275.

https://doi.org/10.1523/JNEUROSCI.4394-09.2010

Kumar, N., Manning, T. F., \& Ostry, D. J. (2019). Somatosensory cortex participates in the consolidation of human motor memory. PLoS Biology, 17(10), 1-21.

https://doi.org/10.1371/journal.pbio.3000469

Landa, R., \& Garrett-Mayer, E. (2006). Development in infants with autism spectrum disorders: A prospective study. Journal of Child Psychology and Psychiatry and Allied Disciplines, 47(6), 629-638. https://doi.org/10.1111/j.1469-7610.2006.01531.x

Libertus, K., Sheperd, K. A., Ross, S. W., \& Landa, R. J. (2014). Limited Fine Motor and Grasping Skills in 6-Month-Old Infants at High Risk for Autism. 85(6), 2218-2231. https://doi.org/10.1111/cdev.12262

Licari, M. K., Alvares, G. A., Varcin, K., Evans, K. L., Cleary, D., Reid, S. L., Glasson, E. J., Bebbington, K., Reynolds, J. E., Wray, J., \& Whitehouse, A. J. O. (2020). Prevalence of Motor Difficulties in Autism Spectrum Disorder: Analysis of a Population-Based Cohort. Autism Research, 13, 298-306. https://doi.org/10.1002/aur.2230

Linke, A., Kinnear, M., Kohli, J., Fong, C., Lincoln, A., Carper, R., \& Müller, R.-A. (2019). Impaired motor skills and atypical functional connectivity of the sensorimotor system in 4065 year old adults with Autism Spectrum Disorders. Neurobiology of Aging, 85, 104-112.

Lloyd, M., MacDonald, M., \& Lord, C. (2013). Motor skills of toddlers with autism spectrum disorders. Autism, 17(2), 133-146. https://doi.org/10.1177/1362361311402230

Lord, C., Rutter, M., DiLavore, P., \& Risi, S. (2002). The autism diagnostic observation scale (ADOS). Los Angeles, CA: Western Psychological.

Mahajan, R., Dirlikov, B., Crocetti, D., \& Mostofsky, S. H. (2016). Motor Circuit Anatomy in Children with Autism Spectrum Disorder With or Without Attention Deficit Hyperactivity Disorder. Autism Research, 9(1), 67-81. https://doi.org/10.1186/s40945-017-0033-9.Using

Manita, S., Suzuki, T., Homma, C., Matsumoto, T., Odagawa, M., Yamada, K., Ota, K., Matsubara, C., Inutsuka, A., Sato, M., Ohkura, M., Yamanaka, A., Yanagawa, Y., Nakai, J., Hayashi, Y., Larkum, M. E., \& Murayama, M. (2015). A Top-Down Cortical Circuit for Accurate Sensory Perception. Neuron, 86(5), 1304-1316. https://doi.org/10.1016/j.neuron.2015.05.006

Markou, P., Ahtam, B., \& Papadatou-Pastou, M. (2017). Elevated Levels of Atypical Handedness in Autism: Meta-Analyses. Neuropsychology Review, 27(3), 258-283. https://doi.org/10.1007/s11065-017-9354-4

Matyas, F., Sreenivasan, V., Marbach, F., Wacongne, C., Barsy, B., Mateo, C., Aronoff, R., \& Petersen, C. C. H. (2010). Motor control by sensory cortex. Science, 330, 1240-1244.

McCarthy, P. (2018). FSLeyes.

Müller, R. A., Cauich, C., Rubio, M. A., Mizuno, A., \& Courchesne, E. (2004). Abnormal activity patterns in premotor cortex during sequence learning in autistic patients. Biological Psychiatry, 56(5), 323-332. https://doi.org/10.1016/j.biopsych.2004.06.007

Mutha, P. K., Haaland, K. Y., \& Sainsburg, R. L. (2012). The effects of brain lateralization on motor control and adaptation. J Mot Behav, 44(6), 455-469. https://doi.org/10.1080/00222895.2012.747482.THE

Nazeri, A., Chakravarty, M. M., Rajji, T. K., Felsky, D., Rotenberg, D. J., Mason, M., Xu, L. N., Lobaugh, N. J., Mulsant, B. H., \& Voineskos, A. N. (2015). Superficial white matter as a novel substrate of age-related cognitive decline. Neurobiology of Aging, 36(6), 2094-2106. https://doi.org/10.1016/j.neurobiolaging.2015.02.022 
medRxiv preprint doi: https://doi.org/10.1101/2021.07.16.21260584; this version posted July 20, 2021. The copyright holder for this preprint

(which was not certified by peer review) is the author/funder, who has granted medRxiv a license to display the preprint in perpetuity. It is made available under a CC-BY-NC-ND 4.0 International license .

Nickl-Jockschat, T., Habel, U., Michel, T. M., Manning, J., Laird, A. R., Fox, P. T., \& Schneider, F. (2012). Brain Structure Anomalies in Autism Spectrum Disorder — A MetaAnalysis of VBM Studies Using Anatomic Likelihood Estimation. Human Brain Mapping, 33, 1470-1489. https://doi.org/10.1002/hbm.21299

Oldfield, R. C. (1971). The assessment and analysis of handedness: The Edinburgh inventory. Neuropsychologia, 9(1), 97-113. https://doi.org/10.1016/0028-3932(71)90067-4

Ostwald, S. K., Snowdon, D. A., Rysavy, S. D. M., Keenan, N. L., \& Kane, R. L. (1989). Manual Dexterity as a Correlate of Dependency in the Elderly. Journal of the American Geriatrics Society, 37(10), 963-969. https://doi.org/10.1111/j.1532-5415.1989.tb07282.x

Pan, C. (2014). Motor proficiency and physical fitness in adolescent males with and without autism spectrum disorders. Autism, 18(2), 156-165. https://doi.org/10.1177/1362361312458597

Partida, G. C., Tung, J. Y., Eriksson, N., Albrecht, E., Aliev, F., Ole, A., Barroso, I., Beckmann, J. S., Boks, M. P., Dorret, I., Boyd, H. A., Breteler, M. M. B., Campbell, H., Daniel, I., Geller, F., Gieger, C., Giegling, I., Gordon, S. D., Loos, R. J. F., ... Medland, S. E. (2020). Genome-wide association study identifies 49 common genetic variants associated with handedness . Nature Human Behaviour, 1-10.

Pavlides, C., Miyashita, E., \& Asanuma, H. (1993). Projection from the sensory to the motor cortex is important in learning motor skills in the monkey. Journal of Neurophysiology, 70(2), 733-741. https://doi.org/10.1152/jn.1993.70.2.733

Penfield, W., \& Boldrey, E. (1937). Somatic Motor and Sensory Representation in the cerebral cortex of man as studied by electrical stimulation. Brain: A Journal of Neurology, 60, 389443. https://doi.org/10.1093/brain/60.4.389

Perelle, I. B., \& Ehrman, L. (2005). On the Other Hand. Behavior Genetics, 35(3), 343-350. https://doi.org/10.1007/s10519-005-3226-z

Peters, N., Müller-Schunk, S., Freilinger, T., Düring, M., Pfefferkorn, T., \& Dichgans, M. (2009). Ischemic stroke of the cortical "hand knob" area: Stroke mechanisms and prognosis. Journal of Neurology, 256(7), 1146-1151. https://doi.org/10.1007/s00415-009-5104-8

Piven, J., \& Rabins, P. (2011). Autism spectrum disorders in older adults: Toward defining a research agenda. Journal of the American Geriatrics Society, 59(11), 2151-2155. https://doi.org/10.1111/j.1532-5415.2011.03632.x

Postema, M. C., van Rooij, D., Anagnostou, E., Arango, C., Auzias, G., Behrmann, M., Filho, G. B., Calderoni, S., Calvo, R., Daly, E., Deruelle, C., Di Martino, A., Dinstein, I., Duran, F. L. S., Durston, S., Ecker, C., Ehrlich, S., Fair, D., Fedor, J., ... Francks, C. (2019). Altered structural brain asymmetry in autism spectrum disorder in a study of 54 datasets. Nature Communications, 10(1), 1-12. https://doi.org/10.1038/s41467-019-13005-8

Pron, A., Deruelle, C., \& Coulon, O. (2021). U-shape short-range extrinsic connectivity organisation around the human central sulcus. Brain Structure and Function, 226(1), 179193. https://doi.org/10.1007/s00429-020-02177-5

Provost, B., Lopez, B. R., \& Heimerl, S. (2007). A Comparison of Motor Delays in Young Children: Autism Spectrum Disorder, Developmental Delay, and Developmental Concerns. Journal of Autism and Developmental Disorders, 37, 321-328. https://doi.org/10.1007/s10803-006-0170-6

Rademacher, J., Bürgel, U., Geyer, S., Schormann, T., Schleicher, A., Freund, H. J., \& Zilles, K. (2001). Variability and asymmetry in the human precentral motor system: A cytoarchitectonic and myeloarchitectonic brain mapping study. Brain, 124(11), 2232-2258. 
medRxiv preprint doi: https://doi.org/10.1101/2021.07.16.21260584; this version posted July 20, 2021. The copyright holder for this preprint

(which was not certified by peer review) is the author/funder, who has granted medRxiv a license to display the preprint in perpetuity.

It is made available under a CC-BY-NC-ND 4.0 International license .

https://doi.org/10.1093/brain/124.11.2232

Rademacher, J., Rademacher, J., Caviness, V. S., Steinmetz, H., \& Galaburda, A. M. (1993).

Topographical variation of the human primary cortices: implications for neuroimaging, brain mapping, and neurobiology. Cerebral Cortex, 3(4), 313-329.

https://doi.org/10.1093/cercor/3.4.313

Ranganathan, V. K., Siemionow, V., Sahgal, V., \& Yue, G. H. (2001). Effects of aging on hand function. Journal of the American Geriatrics Society, 49(11), 1478-1484.

https://doi.org/10.1046/j.1532-5415.2001.4911240.x

Rantanen, T., Guralnik, J. M., Foley, D., Masaki, K., Leveille, S., Curb, J. D., \& White, L. (1999). Midlife hand grip strength as a predictor of old age disability. Journal of the American Medical Association, 281(6), 558-560. https://doi.org/10.1001/jama.281.6.558

Rojkova, K., Volle, E., Urbanski, M., Humbert, F., Dell???Acqua, F., \& Thiebaut De Schotten, M. (2015). Atlasing the frontal lobe connections and their variability due to age and education: a spherical deconvolution tractography study. Brain Structure and Function, 221(3), 1751-1766. https://doi.org/10.1007/s00429-015-1001-3

Rose, S, Rowland, T., Pannek, K., Baumann, F., Coulthard, A., McCombe, P., \& Henderson, R. (2012). Structural hemispheric asymmetries in the human precentral gyrus hand representation. Neuroscience, 210, 211-221.

https://doi.org/10.1016/j.neuroscience.2012.02.044

Rose, Stephen, Guzzetta, A., Pannek, K., \& Boyd, R. (2011). MRI Structural Connectivity , Disruption of Primary Sensorimotor Pathways, and Hand Function in Cerebral Palsy. 1(4). https://doi.org/10.1089/brain.2011.0034

Sacrey, L. R., Zwaigenbaum, L., Bryson, S., Brian, J., \& Smith, I. M. (2018). The reach-to-grasp movement in infants later diagnosed with autism spectrum disorder: a high-risk sibling cohort study. Journal of Neurodevelopmental Disorders, 10(41), 1-11.

Säisänen, L., Määttä, S., Julkunen, P., Niskanen, E., Kallioniemi, E., Gröhn, H., Kemppainen, S., Lakka, T. A., Lintu, N., Eloranta, A. M., Vanninen, R., Makkonen, I., \& Könönen, M. (2019). Functional and structural asymmetry in primary motor cortex in Asperger syndrome: a navigated TMS and imaging study. Brain Topography, 32(3), 504-518. https://doi.org/10.1007/s10548-019-00704-0

Sampaio-Baptista, C., \& Johansen-Berg, H. (2017). White Matter Plasticity in the Adult Brain. Neuron, 96(6), 1239-1251. https://doi.org/10.1016/j.neuron.2017.11.026

Shinoura, N., Suzuki, Y., Yamada, R., Kodama, T., Takahashi, M., \& Yagi, K. (2005). Fibers connecting the primary motor and sensory areas play a role in grasp stability of the hand. NeuroImage, 25(3), 936-941. https://doi.org/10.1016/j.neuroimage.2004.12.060

Smith, R. E., Tournier, J.-D., Calamante, F., \& Connelly, A. (2012). Anatomically-constrained tractography: Improved diffusion MRI streamlines tractography through effective use of anatomical information. NeuroImage, 62(3), 1924-1938. https://doi.org/10.1016/j.neuroimage.2012.06.005

Starkstein, S., Gellar, S., Parlier, M., Payne, L., \& Piven, J. (2015). High rates of parkinsonism in adults with autism. Journal of Neurodevelopmental Disorders, 7(1), 1-11. https://doi.org/10.1186/s11689-015-9125-6

Sun, Z. Y., Klöppel, S., Rivière, D., Perrot, M., Frackowiak, R., Siebner, H., \& Mangin, J. F. (2012). The effect of handedness on the shape of the central sulcus. NeuroImage, 60(1), 332-339. https://doi.org/10.1016/j.neuroimage.2011.12.050

Sun, Z. Y., Pinel, P., Riviere, D., Moreno, A., Dehaene, S., \& Mangin, J.-F. (2016). Linking 
medRxiv preprint doi: https://doi.org/10.1101/2021.07.16.21260584; this version posted July 20, 2021. The copyright holder for this preprint

(which was not certified by peer review) is the author/funder, who has granted medRxiv a license to display the preprint in perpetuity. It is made available under a CC-BY-NC-ND 4.0 International license .

morphological and functional variability in hand movement and silent reading. Brain

Structure and Function, 221, 3361-3371. https://doi.org/10.1007/s00429-015-1106-8

Team, R. C. (2019). R: A Language and Environment for Statistical Computing. R Foundation for Statistical Computing. http://www.r-project.org/

Thompson, A., Murphy, D., Dell'Acqua, F., Ecker, C., McAlonan, G., Howells, H., BaronCohen, S., Lai, M. C., \& Lombardo, M. V. (2017). Impaired Communication Between the Motor and Somatosensory Homunculus Is Associated With Poor Manual Dexterity in Autism Spectrum Disorder. Biological Psychiatry, 81, 211-219. https://doi.org/10.1016/j.biopsych.2016.06.020

Tournier, J. D., Smith, R., Raffelt, D., Tabbara, R., Dhollander, T., Pietsch, M., Christiaens, D., Jeurissen, B., Yeh, C. H., \& Connelly, A. (2019). MRtrix3: A fast, flexible and open software framework for medical image processing and visualisation. NeuroImage, 202(August), 116137. https://doi.org/10.1016/j.neuroimage.2019.116137

Travers, B. G., Bigler, E. D., Duffield, T. C., Prigge, M. D. B., Froehlich, A. L., Lange, N., Alexander, A. L., \& Lainhart, J. E. (2017). Longitudinal development of manual motor ability in autism spectrum disorder from childhood to mid-adulthood relates to adaptive daily living skills. Developmental Science, 20(4), 1-15. https://doi.org/10.1111/desc.12401

Travers, B. G., Bigler, E. D., Tromp, D. P. M., Adluru, N., Destiche, D., Samsin, D., Froehlich, A., Prigge, M. D. B., Duffield, T. C., Lange, N., Alexander, A. L., \& Lainhart, J. E. (2015). Brainstem White Matter Predicts Individual Differences in Manual Motor Difficulties and Symptom Severity in Autism. Journal of Autism and Developmental Disorders, 45(9), 3030-3040. https://doi.org/10.1007/s10803-015-2467-9

Umeda, T., Isa, T., \& Nishimura, Y. (2019). The somatosensory cortex receives information about motor output. Science Advances, 5(7). https://doi.org/10.1126/sciadv.aaw5388

Veldman, M. P., Maurits, N. M., Zijdewind, I., Maffiuletti, N. A., van Middelkoop, S., Mizelle, J. C., \& Hortobágyi, T. (2018). Somatosensory electrical stimulation improves skill acquisition, consolidation, and transfer by increasing sensorimotor activity and connectivity. Journal of Neurophysiology, 120(1), 281-290. https://doi.org/10.1152/jn.00860.2017

Veraart, J., Novikov, D., Christiaens, D., Ades-aron, B., Sijbers, J., \& Fieremans, E. (2016). Denoising of diffusion MRI using random matrix theory Jelle. Neuroimage, 142, 394-406. https://doi.org/10.1177/0164027515620239.Perceived

Viganò, L., Fornia, L., Rossi, M., Howells, H., Leonetti, A., Puglisi, G., Conti Nibali, M., Bellacicca, A., Grimaldi, M., Bello, L., \& Cerri, G. (2019). Anatomo-functional characterisation of the human "hand-knob": A direct electrophysiological study. Cortex, 113, 239-254. https://doi.org/10.1016/j.cortex.2018.12.011

Volkmann, J., Schnitzler, A., Witte, O. W., \& Freund, H. J. (1998). Handedness and asymmetry of hand representation in human motor cortex. Journal of Neurophysiology, 79(4), 21492154. https://doi.org/10.1152/jn.1998.79.4.2149

Vos, S. B., Jones, D. K., Viergever, M. A., \& Leemans, A. (2011). Partial volume effect as a hidden covariate in DTI analyses. NeuroImage, 55(4), 1566-1576. https://doi.org/10.1016/j.neuroimage.2011.01.048

Wechsler, D. (2011). WASI-II: Wechsler abbreviated scale of intelligence. Pearson.

White, L. E., Andrews, T. J., Hulette, C., Richards, A., Groelle, M., Paydarfar, J., \& Purves, D. (1997). Structure of the human sensorimotor system. I: Morphology and cytoarchitecture of the central sulcus. Cerebral Cortex, 7(1), 18-30. https://doi.org/10.1093/cercor/7.1.18

White, N., Roddey, C., Shankaranarayanan, A., Han, E., Rettmann, D., Santos, J., Kuperman, J., 
medRxiv preprint doi: https://doi.org/10.1101/2021.07.16.21260584; this version posted July 20, 2021. The copyright holder for this preprint

(which was not certified by peer review) is the author/funder, who has granted medRxiv a license to display the preprint in perpetuity.

It is made available under a CC-BY-NC-ND 4.0 International license .

\& Dale, A. (2010). PROMO: Real-time prospective motion correction in MRI using imagebased tracking. Magnetic Resonance in Medicine, 63(1), 91-105.

https://doi.org/10.1002/mrm.22176

Whitfield-Gabrieli, S., \& Nieto-Castanon, A. (2012). Conn: A Functional Connectivity Toolbox for Correlated and Anticorrelated Brain Networks. Brain Connectivity, 2(3), 125-141. https://doi.org/10.1089/brain.2012.0073

Wickham, H. (2016). ggplot2: Elegant Graphics for Data Analysis. Springer-Verlag New York.

Willett, F. R., Deo, D. R., Avansino, D. T., Rezaii, P., Hochberg, L. R., Henderson, J. M., \& Shenoy, K. V. (2020). Hand Knob Area of Premotor Cortex Represents the Whole Body in a Compositional Way. Cell, 181, 396-409. https://doi.org/10.1016/j.cell.2020.02.043

Yousry, T. A., Schmid, U. D., Alkadhi, H., Schmidt, D., Peraud, A., Buettner, A., \& Winkler, P. (1997). Localization of the motor hand area to a knob on the precentral gyrus. A new landmark. Brain, 120, 141-157. https://doi.org/10.1093/brain/120.1.141

Zhang, Y., Brady, M., \& Smith, S. (2001). Segmentation of brain MR images through a hidden Markov random field model and the expectation-maximization algorithm. IEEE

Transactions on Medical Imaging, 20(1), 45-57. https://doi.org/10.1109/42.906424 
medRxiv preprint doi: https://doi.org/10.1101/2021.07.16.21260584; this version posted July 20, 2021. The copyright holder for this preprint (which was not certified by peer review) is the author/funder, who has granted medRxiv a license to display the preprint in perpetuity.

\author{
It is made available under a CC-BY-NC-ND 4.0 International license.
}

\title{
Supplementary Material
}


medRxiv preprint doi: https://doi.org/10.1101/2021.07.16.21260584; this version posted July 20, 2021. The copyright holder for this preprint (which was not certified by peer review) is the author/funder, who has granted medRxiv a license to display the preprint in perpetuity.

It is made available under a CC-BY-NC-ND 4.0 International license .

Supplementary Table 1. Frequency and proportion of hand knob shape variants by diagnostic group.

\begin{tabular}{cccccccc}
\hline \multirow{4}{*}{ Group } & & \multicolumn{2}{c}{ Left } & \multicolumn{2}{c}{ Right } & \multicolumn{2}{c}{ Overall } \\
& Shape & $\mathrm{N}$ & $\%$ & $\mathrm{~N}$ & $\%$ & $\mathrm{~N}$ & $\%$ \\
& Omega & 20 & $80.0 \%$ & 20 & $80.0 \%$ & 40 & $80.0 \%$ \\
ASD & Epsilon & 4 & $16.0 \%$ & 5 & $20.0 \%$ & 9 & $18.0 \%$ \\
& Null & 1 & $4.0 \%$ & 0 & $0.0 \%$ & 1 & $2.0 \%$ \\
& Omega & 20 & $83.3 \%$ & 19 & $79.2 \%$ & 39 & $81.3 \%$ \\
TC & Epsilon & 4 & $16.7 \%$ & 4 & $16.7 \%$ & 8 & $16.7 \%$ \\
& Null & 0 & $0.0 \%$ & 1 & $4.2 \%$ & 1 & $2.1 \%$ \\
\hline
\end{tabular}


Supplementary Table 2. Results of ANCOVAs additionally controlling for TBV, RMSD ${ }_{\text {rot }}$ and excluding weakly right-handed individuals.

\begin{tabular}{|c|c|c|c|c|c|}
\hline $\begin{array}{l}\text { Variable additionally controlling } \\
\text { for }\end{array}$ & Region & Measure & df & $p$ & Partial $\eta^{2}$ \\
\hline \multirow{3}{*}{ TBV } & Right $\operatorname{PrC}_{\text {hand }}$ & Volume & 1,45 & 0.013 & 0.129 \\
\hline & $\operatorname{PrC}_{\text {hand }}$ & LI Volume & 1,45 & 0.011 & 0.134 \\
\hline & PoChand & LI Volume & 1,45 & 0.017 & 0.119 \\
\hline \multirow{3}{*}{$\mathrm{RMSD}_{\text {rot }}$} & Right $\operatorname{Pr} \mathrm{C}_{\text {hand }}$ & Volume & 1,45 & 0.009 & 0.143 \\
\hline & $\operatorname{PrC}_{\text {hand }}$ & LI Volume & 1,45 & 0.025 & 0.107 \\
\hline & PoChand & LI Volume & 1,45 & 0.037 & 0.093 \\
\hline \multirow{3}{*}{$\begin{array}{l}\text { Excluding weakly right-handed } \\
\text { individuals }\end{array}$} & Right $\mathrm{PrC}_{\text {hand }}$ & Volume & 1,33 & $<0.001$ & 0.292 \\
\hline & $\operatorname{PrC}_{\text {hand }}$ & LI Volume & 1,33 & 0.001 & 0.327 \\
\hline & PoC $\mathrm{C}_{\text {hand }}$ & LI Volume & 1,33 & 0.009 & 0.185 \\
\hline
\end{tabular}

Abbreviations: $\mathrm{RMSD}_{\mathrm{rot}}=$ Root mean squared deviation in roll, pitch and yaw rotations from MNI standard space. 
Supplementary Table 3. Results of the ANCOVAs performed on the upper and lower pre and postcentral measures and their group means, standard deviations.

\begin{tabular}{|c|c|c|c|c|c|c|c|}
\hline Region & Measure & df & $p$ & $q$ & Partial $\eta^{2}$ & $\mathrm{ASD}$ mean $\pm \mathrm{SD}$ & $\mathrm{TC}$ mean $\pm \mathrm{SD}$ \\
\hline Left $\operatorname{PrC} \mathrm{Cupper}$ & Volume & 1,46 & 0.189 & 0.49 & 0.037 & $2.61 \pm 0.84$ & $2.93 \pm 0.83$ \\
\hline Right $\operatorname{PrC}_{\text {upper }}$ & Volume & 1,45 & 0.180 & 0.49 & 0.040 & $2.82 \pm 0.83$ & $3.18 \pm 0.99$ \\
\hline Left $\mathrm{PoC}_{\text {upper }}$ & Volume & 1,46 & 0.050 & 0.18 & 0.081 & $1.47 \pm 0.49$ & $1.97 \pm 0.83$ \\
\hline Right $\mathrm{PoC}_{\text {upper }}$ & Volume & 1,45 & 0.819 & 0.92 & 0.001 & $1.78 \pm 0.76$ & $1.74 \pm 0.61$ \\
\hline $\mathrm{PrC}_{\text {upper }}$ & LI Volume & 1,45 & 0.942 & 0.94 & $<.001$ & $-7.4 \pm 31.5$ & $-6.7 \pm 35.4$ \\
\hline \multirow[t]{2}{*}{ PoC $_{\text {upper }}$} & LI Volume & 1,45 & 0.353 & 0.56 & 0.019 & $-8.0 \pm 49.9$ & $5.1 \pm 17.5$ \\
\hline & FA & 1,43 & 0.343 & 0.56 & 0.021 & $0.33 \pm 0.04$ & $0.34 \pm 0.03$ \\
\hline \multirow[t]{3}{*}{ Left PoC-PrC $\mathrm{Cupper}_{\mathrm{u} \text {-fibers }}$} & $\mathrm{MD}$ & 1,43 & 0.279 & 0.56 & 0.027 & $7.48 \pm 0.28$ & $7.39 \pm 0.28$ \\
\hline & Volume & 1,43 & 0.374 & 0.56 & 0.018 & $12.91 \pm 3.06$ & $13.87 \pm 4.69$ \\
\hline & FA & 1,44 & 0.237 & 0.53 & 0.032 & $0.33 \pm 0.03$ & $0.34 \pm 0.04$ \\
\hline \multirow[t]{3}{*}{ Right PoC-PrC $\mathrm{Cupper}_{\mathrm{u} \text {-fibers }}$} & MD & 1,44 & 0.007 & 0.13 & $0.152^{\mathrm{a}}$ & $7.47 \pm 0.35$ & $7.23 \pm 0.24$ \\
\hline & Volume & 1,44 & 0.550 & 0.75 & 0.008 & $12.82 \pm 3.62$ & $13.69 \pm 5.75$ \\
\hline & LI FA & 1,43 & 0.905 & 0.94 & $<.001$ & $0.3 \pm 10.4$ & $0.8 \pm 11.0$ \\
\hline \multirow[t]{2}{*}{ PoC-PrC $\mathrm{upper}_{\mathrm{u} \text {-fibers }}$} & LI MD & 1,43 & 0.040 & 0.18 & 0.095 & $0.3 \pm 2.9$ & $2.2 \pm 3.4$ \\
\hline & LI Volume & 1,43 & 0.667 & 0.80 & 0.004 & $0.6 \pm 24.5$ & $3.7 \pm 36.0$ \\
\hline Left PoC-PrC $\mathrm{upper}_{\mathrm{f}}$ & $\mathrm{FC}$ & 1,38 & 0.015 & 0.14 & $0.145^{\mathrm{a}}$ & $1.11 \pm 0.36$ & $1.38 \pm 0.43$ \\
\hline Right PoC-PrC $\mathrm{Cupper}$ & $\mathrm{FC}$ & 1,38 & 0.025 & 0.15 & $0.126^{\mathrm{a}}$ & $1.10 \pm 0.31$ & $1.37 \pm 0.40$ \\
\hline PoC-PrC $\mathrm{Cupper}$ & LI FC & 1,38 & 0.586 & 0.75 & 0.008 & $-1.6 \pm 25.7$ & $-0.1 \pm 33.7$ \\
\hline Left $\operatorname{PrC}$ lower & Volume & 1,46 & 0.536 & 0.90 & 0.008 & $8.69 \pm 1.33$ & $8.94 \pm 1.37$ \\
\hline Right $\operatorname{PrC}_{\text {lower }}$ & Volume & 1,46 & 0.564 & 0.90 & 0.007 & $8.49 \pm 1.13$ & $8.69 \pm 1.25$ \\
\hline Left PoClower & Volume & 1,46 & 0.421 & 0.90 & 0.014 & $5.89 \pm 0.81$ & $5.67 \pm 1.13$ \\
\hline Right $\mathrm{PoC}_{\text {lower }}$ & Volume & 1,46 & 0.412 & 0.90 & 0.015 & $5.13 \pm 1.15$ & $5.42 \pm 1.29$ \\
\hline $\operatorname{PrC}$ lower & LI Volume & 1,46 & 0.904 & 0.90 & $<.001$ & $2.2 \pm 15.9$ & $2.7 \pm 11.7$ \\
\hline
\end{tabular}




\begin{tabular}{|c|c|c|c|c|c|c|c|}
\hline PoClower & LI Volume & 1,46 & 0.068 & 0.61 & 0.071 & $15.3 \pm 20.6$ & $5.1 \pm 17.5$ \\
\hline \multirow{3}{*}{ Left PoC-PrC $\mathrm{C}_{\text {lower }} \mathrm{u}$-fibers } & FA & 1,44 & 0.800 & 0.90 & 0.001 & $0.33 \pm 0.02$ & $0.33 \pm 0.02$ \\
\hline & MD & 1,44 & 0.725 & 0.90 & 0.003 & $7.14 \pm 0.23$ & $7.12 \pm 0.22$ \\
\hline & Volume & 1,44 & 0.795 & 0.90 & 0.002 & $26.10 \pm 4.04$ & $26.01 \pm 5.26$ \\
\hline \multirow{3}{*}{ Right PoC-PrC $C_{\text {lower }} \mathrm{u}$-fibers } & FA & 1,44 & 0.883 & 0.90 & $<.001$ & $0.32 \pm 0.02$ & $0.33 \pm 0.03$ \\
\hline & MD & 1,44 & 0.189 & 0.88 & 0.039 & $7.18 \pm 0.25$ & $7.08 \pm 0.23$ \\
\hline & Volume & 1,44 & 0.863 & 0.90 & 0.001 & $25.38 \pm 4.09$ & $25.99 \pm 4.95$ \\
\hline \multirow{3}{*}{ PoC-PrC $\mathrm{Clwer}_{\mathrm{u}} \mathrm{u}$-fibers } & LI FA & 1,44 & 0.717 & 0.90 & 0.003 & $3.0 \pm 7.0$ & $1.4 \pm 7.8$ \\
\hline & LI MD & 1,44 & 0.195 & 0.88 & 0.038 & $-0.6 \pm 2.6$ & $0.6 \pm 2.3$ \\
\hline & LI Volume & 1,44 & 0.527 & 0.90 & 0.009 & $3.0 \pm 17.7$ & $-0.5 \pm 16.9$ \\
\hline Left PoC-PrClower & $\mathrm{FC}$ & 1,38 & 0.023 & 0.41 & $0.129^{\mathrm{a}}$ & $1.18 \pm 0.24$ & $1.48 \pm 0.50$ \\
\hline Right PoC-PrC lower & $\mathrm{FC}$ & 1,38 & 0.273 & 0.90 & 0.032 & $1.28 \pm 0.36$ & $1.39 \pm 0.49$ \\
\hline PoC-PrC $C_{\text {lower }}$ & LI FC & 1,38 & 0.321 & 0.90 & 0.026 & $-11.1 \pm 19.1$ & $6.6 \pm 25.4$ \\
\hline
\end{tabular}

${ }^{a}$ Large size group effects (partial $\left.\eta^{2}>.12\right)$.

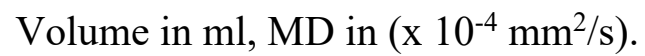

3 extreme outliers ( $>3$ SD from the mean) were removed for $\operatorname{PrC}_{\text {upper }}$ volume ( 1 participant), $\operatorname{PoC}$ upper volume (1 participant), left

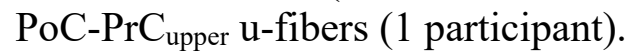


medRxiv preprint doi: https://doi.org/10.1101/2021.07.16.21260584; this version posted July 20, 2021. The copyright holder for this preprint (which was not certified by peer review) is the author/funder, who has granted medRxiv a license to display the preprint in perpetuity.

It is made available under a CC-BY-NC-ND 4.0 International license .
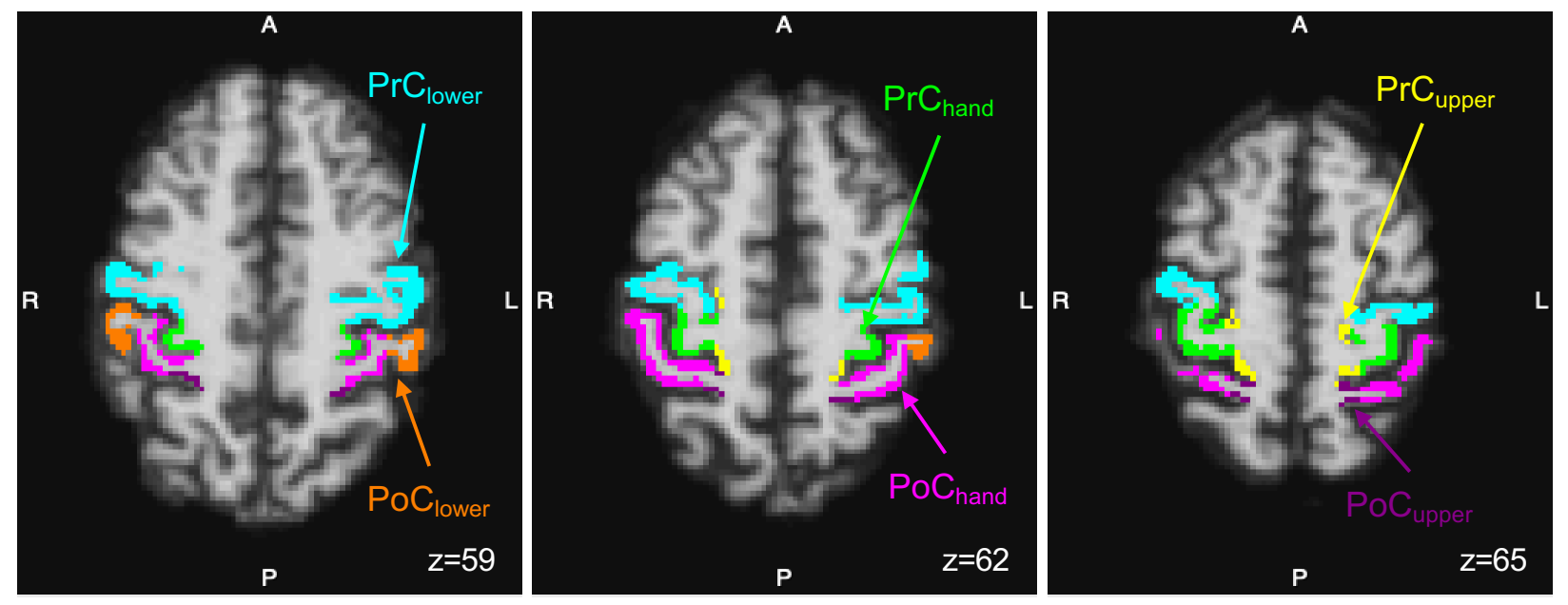

Supplementary Figure 1. PrC and PoC sub-parcels shown on multiple axial slices in a representative participant with ASD. 


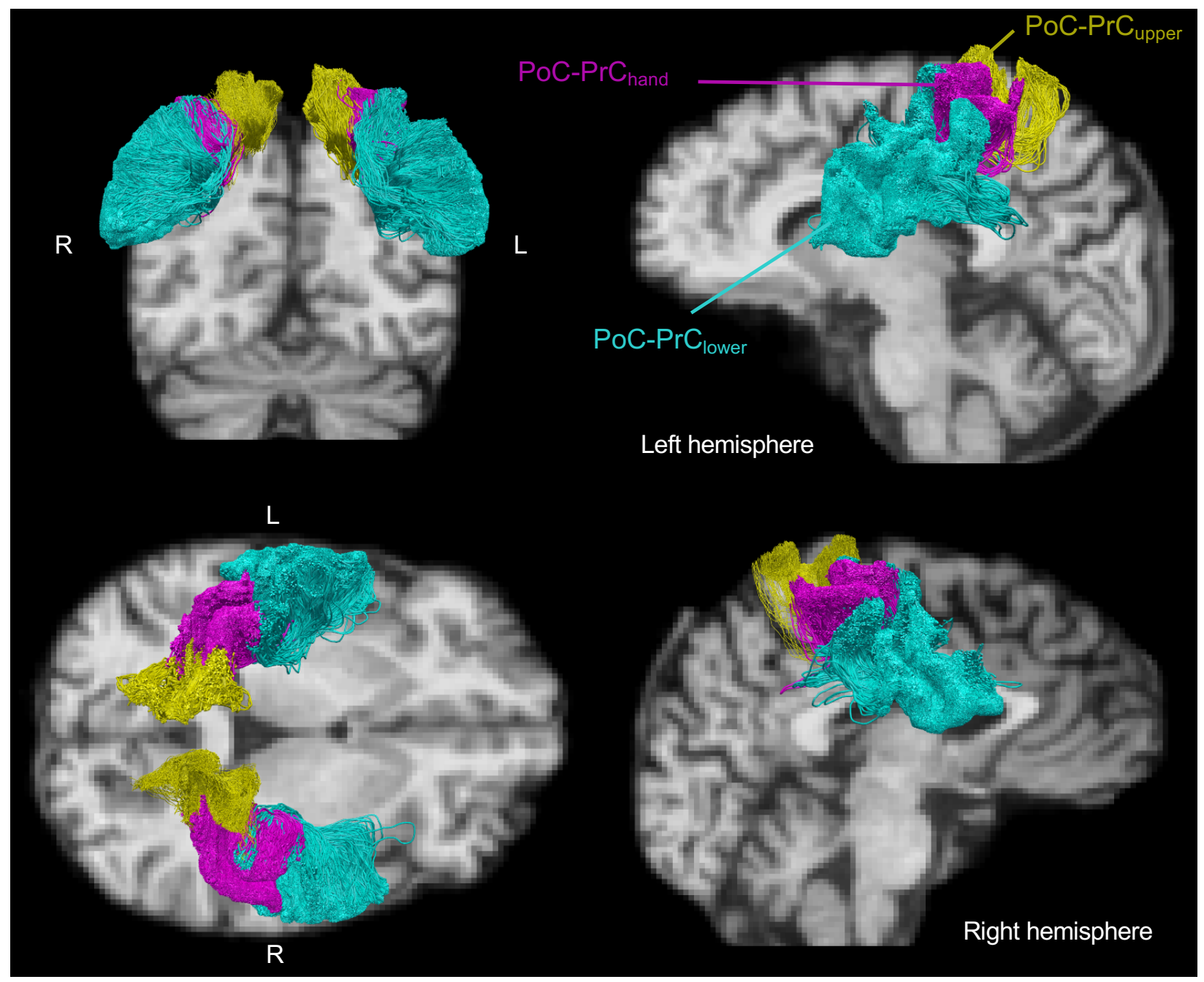

Supplementary Figure 2. PoC-PrC u-fiber sub-tracts corresponding to PrC and PoC sub-parcels shown from multiple angles in native diffusion space with a T1-weighted underlay in a representative participant with ASD. 


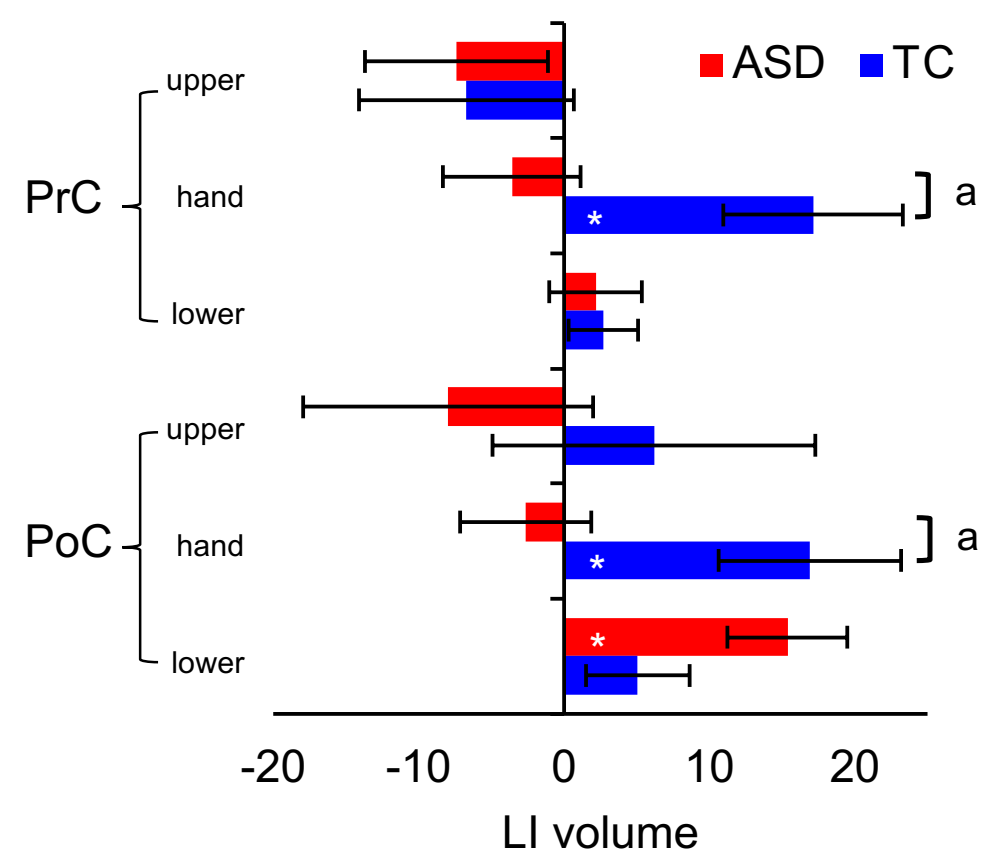

Supplementary Figure 3. Laterality index of volume in the pre and postcentral sub-parcels (upper, hand knob, and lower). Significant at a $q<.10$ (group difference); ${ }^{*} p<.05$, uncorrected (differs from zero). 